\title{
Charity, Status, and Optimal Taxation: Welfarist and Paternalist Approaches*
}

\author{
Thomas Aronsson a \\ Olof Johansson-Stenman $b$ \\ Ronald Wendner $\mathrm{c}$ \\ a Department of Economics, Umeå School of Business, Economics and Statistics, Umeå \\ University, Sweden \\ b Department of Economics, School of Business, Economics and Law, University of \\ Gothenburg, Sweden \\ c Department of Economics, University of Graz, Austria
}

\begin{abstract}
April 2019

This paper deals with tax policy responses to charitable giving, defined in terms of voluntary contributions to a public good, to which the government also contributes through public revenue; the set of tax instruments contains general, nonlinear taxes on income and charitable giving. In addition to consumption, leisure and a public good, individuals obtain utility from the warm glow of giving and social status generated by their relative contributions to charity as well as their relative consumption compared with others. We analyze the conditions under which it is optimal to tax or subsidize charitable giving and derive corresponding optimal policy rules. Another aim of the paper is to compare the optimal tax policy and public good provision by a conventional welfarist government with those by two kinds of paternalist governments: The first kind does not respect the consumer preferences for status in terms of relative giving and relative consumption, while the second kind in addition does not respect preferences for warm glow of giving. The optimal policy rules for marginal taxation and public good provision are similar across governments, except for the stronger incentive to tax charitable giving at the margin under the more extensive kind of paternalism. Numerical simulations supplement the theoretical results.
\end{abstract}

Keywords: Conspicuous consumption, conspicuous charitable giving, optimal taxation, warm glow.

JEL Classification: D03, D62, H21, H23

\footnotetext{
* The authors would like to thank David Granlund, Volker Meier, Katarina Nordblom, and Tomas Sjögren for helpful comments and suggestions. The paper has been presented at seminars at Freie Universität, Berlin, the University of Gothenburg, Linnaeus University, and Umeå University, as well as at the European Public Choice Society conference held in Jerusalem 2019, and the authors would like to thank the participants for valuable discussions. Research grants from The Marianne and Marcus Wallenberg Foundation (MMW 2015.0037) are gratefully acknowledged.
} 


\section{Introduction}

Individuals and organizations donate substantial amounts to charities, not least in the United States where in 2017 charitable giving amounted to more than $\$ 400$ billion, or more than 2 percent of GDP (Giving USA, 2018). Some of this charitable giving resembles direct redistribution from donors to receivers (e.g., donations to various human services aimed at providing food and shelter), whereas the bulk of the donations is better described as voluntary contributions to public goods or community services, e.g., research, religious and environmental organizations, education programs, and public-society benefit charities (Giving USA, 2018). Considering the large amounts of resources that people give to charity, an important policy question is whether charitable giving ought to be encouraged or discouraged via the tax system. This is a non-trivial question, illustrated by the fact that public policies related to charitable giving vary largely both between countries and within countries over time (Fack and Landais, 2012). The present paper addresses this question by developing and analyzing a model where individuals give to charity through voluntary contributions to a public good, to which there is also potential public provision, and where the government collects revenue and redistributes through a nonlinear income tax. In doing so, we take a broad perspective by examining the potential, simultaneous roles that the warm glow of giving and status concerns may play for behavior and public policy, as well as distinguish between the policies decided on by welfarist and paternalist governments. We describe our contribution and approach more thoroughly below.

Our model is based on the optimal nonlinear income tax problem pioneered by Mirrlees (1971), adapted to a discrete two-ability-types version by Stern (1982) and Stiglitz (1982), and augmented by public good provision by Boadway and Keen (1993). In such a framework, individual productivity is private information and thus not observable to the government, and the set of available policy instruments are based on information limitations rather than a priori restrictions on the tax instruments. This basic workhorse model is here extended by adding (1) voluntary contributions to the public good alongside the public provision, (2) warm-glow preferences for contributions to the public good, (3) status concerns for charitable contributions, such that people prefer to give more than others, and (4) status concerns with respect to private consumption. Related to Extension 1, our model assumes that individual 
charitable giving, in addition to income, is observable, ${ }^{1}$ meaning that both of them are subject to general, nonlinear taxation (or subsidization). Extensions (3) and (4) together imply that our model allows for multiple positional externalities related to (status driven) concerns regarding relative consumption and relative charitable giving, respectively. This is well motivated from the point of view of the marginal tax treatment of charitable giving, which typically depends on both types of relative concerns. It is also motivated based on the empirical evidence referred to in Section 2.

Together with our companion paper, Aronsson, Johansson-Stenman, and Wendner (2018; see Section 2), the present study is (to our knowledge) the first to analyze charitable giving in the Mirrlees-Stern-Stiglitz framework of optimal nonlinear taxation. ${ }^{2}$ It is also the first paper dealing with policy responses to charitable giving that simultaneously addresses (1)-(4) above in any kind of model. As we will argue below, this means that the paper takes a much broader perspective on social comparisons than earlier comparable research.

Another important contribution is that we distinguish, in a systematic way, between a conventional welfarist government, i.e., one that respects all aspects of consumer preferences and forms the social objective thereupon, and paternalist governments that do not respect all aspects of consumer preferences when forming the social objective. Although welfarism is a standard assumption in normative economics, it is by no means obvious when social comparisons are involved. The reason is that such comparisons can be interpreted as expressions of envy. Indeed, Sen (1979), Harsanyi (1982), and Goodin (1986) have all argued that the government should not respect anti-social preferences, and Harsanyi (1982) explicitly uses envy to exemplify an anti-social preference that should not be part of the social welfare

\footnotetext{
${ }^{1}$ That charitable giving is observable is, of course, a stronger assumption than observability of income. The long history of tax deductions attached to charitable giving, accompanied by the fact that some charities publish the names of the donors (and sometimes the size of the donations), may speak in favor of this assumption. When charitable giving is subsidized, rather than taxed, each individual also has incentives to make the giving observable to the government. This assumption is also quite natural in our setting where charitable giving partly reflects conspicuous consumption. An interesting avenue for future research would be to extend the analysis to a case where charitable giving is only observable in part.

${ }^{2}$ Diamond (2006) analyzes charitable giving based on the model developed in Diamond (1980), i.e., a version of optimal nonlinear taxation in which individuals choose among different types of jobs, while the hours of work are held constant.
} 
function. ${ }^{3}$ This suggests that it would be useful to compare the policies decided on by a welfarist government with those that a paternalist government would choose if respecting all aspects of consumer preferences except the relative concerns. Such a policy objective will be referred to as Type I paternalism. Furthermore, based on arguments presented in Diamond (2006), one can discuss whether consumer preferences for warm glow ought to be reflected in a social cost benefit analysis of charitable giving. Therefore, we also consider a case where the government respects neither the consumer preferences for status (as manifested in the concerns for relative consumption and relative giving) nor the consumer preference for warm glow, and refer to this as Type II paternalism in what follows. In the latter, and more extensive, version of paternalism, an interesting question is thus whether charitable giving is socially desirable, despite that the government shares none of the consumer preferences that drive charitable contributions.

Based on our model, an important separation result is first shown, namely, that the optimal policy rules for marginal income taxation and public good provision take the same form as in the absence of any charitable giving. Thus, the policy rules for marginal income taxation and public good provision under welfarism are analogous to those derived by Aronsson and Johansson-Stenman (2008), and the policy rules for marginal income taxation under paternalism are analogous to those derived by Aronsson and Johansson-Stenman (2018).

The marginal tax treatment of charitable giving is typically found to differ between the two ability types, under both welfarism and (the two types of) paternalism. An exception arises under welfarism in a special case where leisure is weakly separable in terms of the utility function, in which all individuals face the same policy rule for marginal taxation/subsidization of charitable giving. Given interior solutions, such that both ability types contribute to charity, the optimal marginal tax (subsidy) on charity is found to increase (decrease) both with the extent to which people care about relative charitable giving and with the transaction cost associated with such giving, while it decreases (increases) with the extent to which people care about relative consumption. These determinants appear under both welfarism and paternalism, albeit in slightly different forms. This is important to point out because welfarist and paternalist governments have very different reasons for using corrective taxation. Whereas the welfarist government attempts to internalize the positional externalities

\footnotetext{
${ }^{3}$ See Blackorby et al. (2005) for an argument in the opposite direction, namely that such preferences should be part of the social welfare function.
} 
emanating from relative concerns, the paternalist government wants people to behave as if these concerns were absent (and, in the more extensive version of paternalism, as if also the preference for warm glow were absent). The optimal policy rules are, nevertheless, quite similar across governments, except for the much stronger incentive to tax charitable giving at the margin under Type II paternalism. Numerical simulations supplementing the theoretical analysis suggest that charitable giving should typically be subsidized at the margin in our setting. Furthermore, the marginal subsidy rates are quite similar under welfarism and Type I paternalism. Under Type II paternalism, the marginal subsidy rates are much lower and may even turn into marginal taxes. The three regimes also imply quite similar levels of public good provision and overall redistribution policies.

Contrary to much earlier research on optimal taxation and public good provision, which typically (and for good reasons) focuses on interior solutions, cases with one or several corner solutions are potentially very important when dealing with charitable giving. Indeed, it may perfectly well be optimal that individuals of the low-ability type, or individuals of both ability types, contribute nothing, and there are cases where both ability types should contribute but the government should not. For instance, under Type II paternalism (where the government accepts neither the relative concerns nor the consumer preference for warm glow), low-ability individuals should never contribute to charity at the social optimum, while contributions by the high-ability type lead to greater welfare through a relaxation of the self-selection constraint (and may thus be desirable for that reason). Therefore, we present conditions for when it is socially optimal that individuals and/or the government contribute, and when it is not. Moreover, the importance of the warm glow motivation for optimal individual contributions to be positive is highlighted both analytically and based on simulations. We also examine how the marginal tax treatment of the contributors is affected by one or more corner solutions. In particular, charitable giving should be taxed at higher marginal rates (or subsidized at lower marginal rates) if the government does not contribute to the public good. The marginal tax treatment of charitable giving for individuals who should not contribute at all to charity is straightforward: these marginal tax rates should simply be high enough (or the marginal subsidy small enough) to prevent these individuals from contributing.

Overall, the models presented here can be seen as behavioral in the sense that they allow for social comparisons and warm-glow of giving to matter for people (cf. Thaler, 2018). On the other hand, people are nevertheless consistently maximizing their utilities, based on fixed 
preferences, without any errors, in line with what Becker (1993) famously describes as the economic way of looking at behavior.

The remainder of the paper is organized as follows. Section 2 briefly reviews the related empirical and theoretical literature on links between public policy and charitable giving, and Section 3 outlines the model. Section 4 then presents the optimal tax and expenditure policy results based on the conventional welfarist perspective, while the two paternalist approaches are presented in Sections 5 and 6. In Section 7, we supplement the theoretical analyses carried out in Sections 3-6 with extensive numerical simulations. These simulations serve to illustrate how the marginal taxation of income and charitable giving, as well as the overall redistribution, vary with key parameters of the model. Section 8 concludes the paper, and the appendix presents the proofs and mathematical results that support the analysis in the main text.

\section{Related Literature on Public Policy and Charitable Giving}

In addition to the well-established warm-glow motive for charitable giving (e.g., Andreoni, 1989, 1990, 1998), several studies suggest that charitable giving is a means of signaling status or prestige (e.g., Glazer and Konrad, 1996; Harbaugh, 1998a; Cartwright and Patel, 2013; Karlan and McConnell, 2014). Empirical evidence supports this idea by showing that the size and distribution of donations depend on whether they are made publicly observable and, if observable, on the way in which they are reported (e.g., Harbaugh, 1998b; Andreoni and Petrie, 2004; Alpizar et al., 2008), as well as on the contributions made by other people (Andreoni and Petrie, 2004; Alpizar et al., 2008). Harbaugh (1998b) also argues that this prestige motive is likely to be empirically important in the sense that "a substantial portion of donations can be attributed to it" (p. 281). Questionnaire-experimental and happiness research points to a similar status-driven motive for private consumption (influencing the incentives underlying income formation), such that people derive well-being from their relative consumption or income compared with that of referent others; see, e.g., Johansson-Stenman et al. (2002), Solnick and Hemenway (2005), and Carlsson et al. (2007) for evidence based on questionnaire-experimental research, and Easterlin (2001), Blanchflower and Oswald (2004), Ferrer-i-Carbonell (2005), and Clark and Senik (2010) for evidence based on happiness research. In fact, as much as 20-50 percent of the well-being increase from an additional dollar spent on consumption may be attributable to increased relative consumption (Wendner 
and Goulder, 2008). There are also revealed-preference studies finding that people are willing to pay for ways to signal wealth; for example, Bursztyn et al. (2017) find in a natural experiment that the demand for platinum credit cards greatly exceeds demand for a regular credit card with exactly the same functional properties. In a way similar to status motives for giving to charity, relative consumption concerns are directly relevant for policies aimed at influencing charitable giving, since such giving reflects a tradeoff between donations and private consumption.

As we intend to do in the present paper, a number of earlier studies have examined the policy implications of charitable giving in models of optimal taxation, where the donations to charity are described in terms of voluntary contributions to a public good (e.g., Feldstein, 1980; Warr, 1983; Saez, 2004; Diamond, 2006; Blumkin and Sadka, 2007). Saez (2004) shows that the optimal subsidy on voluntary contributions depends on the positive externality that each contributor imposes on other people (as in Warr, 1983), the price sensitivity of the contribution good, and the extent to which direct public contributions crowd out private contributions. Based on the model developed in Diamond (1980), which is a less frequently used model of optimal nonlinear taxation in which the hours of work are fixed, Diamond (2006) derives a second-best argument for marginal subsidies at the top of the income distribution. He shows that voluntary contributions by those with the highest earnings ability lead to a relaxation of the incentive constraint. We derive a similar result below, albeit based on a different underlying mechanism. Blumkin and Sadka (2007) examine a status motive for charitable giving as well as tax policy implications thereof. They consider a model where charitable donations (through voluntary contributions to a public good) signal status, while neglecting the warm-glow motive addressed by Saez and Diamond in their respective studies. By examining the welfare effect of introducing a small tax on charitable giving when the income tax is optimal, they find that the optimal tax on charitable giving is non-negative; it is positive if status concerns would lead to over-provision of the public good and zero otherwise. A result similar to theirs follows as a special case of our model.

Since relative consumption concerns play an important role in the subsequent analysis, our study also builds on literature on relative consumption and optimal public policy (e.g., Boskin and Sheshinski, 1978; Layard, 1980; Oswald, 1983; Dupor and Liu, 2003; Ljungqvist and Uhlig, 2000; Aronsson and Johansson-Stenman, 2008, 2010; Wendner and Goulder, 2008; and Eckerstorfer and Wendner, 2013). This research shows that a consumption externality 
caused by such comparisons introduces a significant element of correction in the tax system, and it also presents conditions under which externality correction facilitates or hinders redistribution (by relaxing or tightening the incentive constraint). We contribute to this literature by considering a case with multiple externalities driven by status seeking, which interact in important ways in terms of the optimal tax policies. Furthermore, recent research has examined optimal income taxation in models where the government is paternalist in the sense of not sharing the consumer preference for relative consumption (Micheletto, 2011; Dodds, 2012; Aronsson and Johansson-Stenman, 2018). A noticeable result is that a paternalist government would implement similar policy rules for marginal taxation, as well as a similar overall redistribution policy, as its welfarist counterpart, albeit for a different reason. We show that these similarities carry over to economies with voluntary contributions to public goods and, in particular, to the marginal tax treatment of charitable giving.

Diamond (2006) argues against using warm-glow preferences as a basis for taxation. A key reason for this stance is that warm glow is likely to be context dependent, suggesting that it is not straightforward to measure this source of welfare benefit in practice. Since Diamond does not address any status motive for charitable giving (or consumption in general), he compares the marginal tax treatment of charitable giving by a welfarist government with that by a paternalist government, which does not respect the consumer preference for warm glow. Furthermore, by recognizing warm glow as a source of benefit, there may also be reasons to devote resources to produce the contexts in which warm glow arises, which is not necessarily a good use of resources. If we were to follow Diamond and disregard warm-glow welfare effects, the case for supporting private charity would be considerably weakened. This motivates us to go further and analyze a more extensive form of paternalism, where the government respects neither the status motives for charitable giving and consumption (as reflected in the relative concerns) nor the consumer preference for warm glow.

As mentioned, Aronsson, Johansson-Stenman, and Wendner (2018) parallel the present paper and share some important model features. Yet, the purpose of that study is quite different as it is concerned with redistribution through charitable giving from the rich to the poor and, therefore, distinguishes between donors and receivers of charity. A major issue is then to analyze possible stigma effects of receiving charity in terms of their influence on the optimal tax structure. Their paper addresses neither charitable contributions to a public good (there is 
no public good at all in that paper) nor any paternalist approach to public policy, both of which are major issues in the present paper.

In brief, while our paper relates to a large literature, it is unique in several important ways. First, it introduces charitable giving (in terms of voluntary contributions to a public good) into the Mirrlees-Stiglitz framework of optimal taxation along with a tax instrument targeting charitable giving. Second, it takes a much broader perspective on social comparisons than earlier studies on optimal income taxation in general and the marginal tax treatment of charitable giving in particular. Third, it systematically distinguishes between the tax policy implemented by a conventional welfarist government and the policies implemented by various types of paternalist governments.

\section{A Model with Social Comparisons and Charitable Giving}

The economy is populated by a fixed number of individuals, of whom $n^{1}$ are of a low-ability type $(i=1)$ and $n^{2}$ are of a high-ability type $(i=2)$. This distinction refers to productivity as measured by the before-tax wage rate. The total population becomes

$$
n^{1}+n^{2}=N \text {. }
$$

Individuals of each type are endowed with one unit of time and supply $0 \leq l^{i} \leq 1$ units of labor. An individual of ability-type $i$ cares about own absolute consumption, $c^{i}$, and leisure, $z^{i} \equiv 1-l^{i}$, and about own consumption relative to a consumption reference level, $\Delta c^{i}=c^{i}-\bar{c}$, where we follow much earlier literature on public policy and relative consumption in assuming

$$
\bar{c} \equiv \frac{n^{1} c^{1}+n^{2} c^{2}}{N} .
$$

Equation (2) means that the consumption reference level is the economy's average level of consumption. The additive specification of relative consumption, given by the difference between the individual's own consumption and the measure of reference consumption, is commonly used in the literature (e.g., Galí, 1994; Akerlof, 1997; Ljungqvist and Uhlig, 2000; Bowles and Park, 2005; and Aronsson and Johansson-Stenman, 2008, 2010, 2014). ${ }^{4}$

\footnotetext{
${ }^{4}$ A quotient formulation, where the individual's relative consumption is given by the ratio of his/her own consumption to the reference measure (as in, e.g., Boskin and Sheshinski, 1978; Layard, 1980; Abel, 2005; and Wendner and Goulder, 2008), would give the same qualitative results as those presented below.
} 
As indicated above, we assume that individuals care about their charitable giving, $g^{i}$, such that each individual prefers to contribute to charity for a given consumption level and thus derives a corresponding warm-glow effect. ${ }^{5}$ People also care about their relative contribution, i.e., how much they give compared with other contributors. Hence, each individual of abilitytype $i$ also cares about $\Delta g^{i}=g^{i}-\bar{g}$, where

$$
\bar{g} \equiv \frac{n^{1} g^{1}+n^{2} g^{2}}{N}
$$

is the average contribution in the economy as a whole, which will serve as our measure of reference giving. This means that the warm-glow effect is not the only motive for charitable giving; individuals also derive utility from giving more than others, and disutility from giving less. ${ }^{6}$

The overall size of the public good, $G$, depends on the sum of individual contributions and the amount provided directly by the government, $G^{G o v}$. In addition, we allow for a potential transaction cost attached to charitable giving such that the overall size of the public good can be written as

$$
G=G^{G o v}+(1-\mu)\left(n^{1} g^{1}+n^{2} g^{2}\right),
$$

where $0 \leq \mu<1$ is a parameter reflecting the transaction cost. ${ }^{7}$

\subsection{Individual Behavior and Production}

The utility function faced by an individual of ability-type $i$ can then be written as

$$
U^{i}=v^{i}\left(c^{i}, z^{i}, g^{i}, \Delta c^{i}, \Delta g^{i}, G\right)=u^{i}\left(c^{i}, z^{i}, g^{i}, \bar{c}, \bar{g}, G\right) .
$$

The function $v^{i}(\cdot)$ defines utility as a function of absolute consumption, leisure, charitable giving, and the public good, respectively, and of the relative consumption and relative

\footnotetext{
${ }^{5}$ Of course, this need not imply that they actually contribute to charity, since such contributions reduce their consumption levels. Hence, we cannot rule out corner solutions of zero giving, which will be discussed subsequently.

${ }^{6}$ For simplicity, we assume economy-wide reference levels for both consumption and charitable giving. Most qualitative insights would prevail in a setting where individuals instead compare their consumption and charitable giving with averages based on their own type only; cf. Aronsson and Johansson-Stenman (2010), who analyze the implications of within-type consumption comparisons for optimal taxation.

${ }^{7}$ There are of course transaction costs also for governmental provision of public goods. It is therefore natural to interpret $\mu$ as a measure of additional transaction costs associated with charitable giving. One might also interpret this measure more broadly as partly reflecting a less optimal, from the society's point of view, distribution of public goods.
} 
charitable giving, while the function $u^{i}(\cdot)$ is a convenient reduced form that helps shorten the notations. We assume that $v^{i}(\cdot)$ is strictly quasi-concave, increasing in $c, z$, and $G$, and non-decreasing in $g, \Delta c$, and $\Delta g .{ }^{8}$ Thus, by using subscripts to denote partial derivatives, the relationships between $u^{i}(\cdot)$ and $v^{i}(\cdot)$ are summarized as follows: $u_{c}^{i}=v_{c}^{i}+v_{\Delta c}^{i}>0$, $u_{z}^{i}=v_{z}^{i}>0, u_{\bar{c}}^{i}=-v_{\Delta c}^{i} \leq 0, u_{g}^{i}=v_{g}^{i}+v_{\Delta g}^{i}>0, u_{\bar{g}}^{i}=-v_{\Delta g}^{i} \leq 0$, and $u_{G}^{i}=v_{G}^{i}>0$. For later use, a special case of the utility function in equation (5) will be defined based on the following notion of leisure separability:

Definition 1. The notion of leisure separability is here defined to mean that the utility function in equation (5) can be written in the following form:

$$
U^{i}=V^{i}\left(k\left(c^{i}, g^{i}, \bar{c}, \bar{g}, G\right), z^{i}, G\right) .
$$

A few remarks are in order: This weak separability structure implies that the marginal rates of substitution between $c^{i}, g^{i}, \bar{c}$, and $\bar{g}$ are all independent of leisure time. The utility functions may vary between ability types, but the sub-utility function $k$ remains the same. That $G$ appears both within and outside of the $k$-function is a generalization of the more restrictive cases where it only appears within or outside the $k$-function. In this way, we allow for the possibilities that the public good may be complementary with or substitutable for leisure, as well as complementary with or substitutable for private consumption, charitable giving, relative consumption, and relative giving, respectively, and that such complementarity and substitutability may vary between ability types.

The budget constraint facing any individual of ability-type $i$ can be written as

$$
w^{i} l^{i}-T\left(w^{i} l^{i}, g^{i}\right)-g^{i}=c^{i},
$$

\footnotetext{
${ }^{8}$ This means that the warm-glow and relative giving components depend on how much the individuals actually give, i.e., $g$. A possible alternative would be to assume that the utility of warm glow and relative giving depends on the giving net of the transaction cost, $g(1-\mu)$, which is a measure of how much other people receive in terms of public good consumption. We have chosen the former approach for primarily two reasons. First, this approach is arguably more consistent with the idea of deriving utility from the act of giving per se. Second, even if the transaction cost may be observable to policy makers, it is not necessarily observable at the individual level. Although our choice of approach is likely to matter numerically, it is not important for the qualitative results as all mechanisms discussed below would still be present under the alternative formulation.
} 
where $w^{i}$ denotes the hourly before-tax wage rate facing ability-type $i$, while $T\left(w^{i} l^{i}, g^{i}\right)$ is a general, non-linear tax function through which the tax payment depends on both income and charitable giving.

Individuals are assumed to be atomistic agents by treating the levels of reference consumption, $\bar{c}$, reference giving, $\bar{g}$, and the public good, $G,{ }^{9}$ as exogenous. Each such individual chooses consumption, work hours, and charitable giving to maximize utility given by equation (5) subject to their respective budget constraints in equation (7). In addition to equation (7), an interior solution satisfies the following first-order conditions for work hours and giving:

$$
\begin{gathered}
M R S_{z, c}^{i} \equiv \frac{u_{z}^{i}}{u_{c}^{i}}=\frac{v_{z}^{i}}{v_{c}^{i}+v_{\Delta c}^{i}}=w^{i}\left(1-T_{w l}^{i}\right) \\
\operatorname{MRS}_{g, c}^{i} \equiv \frac{u_{g}^{i}}{u_{c}^{i}}=\frac{v_{g}^{i}+v_{\Delta g}^{i}}{v_{c}^{i}+v_{\Delta c}^{i}}=1+T_{g}^{i},
\end{gathered}
$$

where $T_{w l}^{i}$ is the marginal income tax rate facing each individual of ability-type $i$ and $T_{g}^{i}$ is the corresponding marginal tax (if positive) or subsidy (if negative) on charitable giving.

Finally, there is a linear production technology with labor as the only input, where the constant marginal cost of production is normalized to one. Given competitive markets, the before-tax wage rates equal the marginal productivity of the respective type.

\subsection{Measuring Relative Concerns}

The marginal tax policy presented below depends on the extent to which the relative consumption and relative charitable giving affect well-being at the individual level. Therefore, let us introduce the following degrees of positionality with respect to consumption, ${ }^{i}$, and charitable giving, $\beta^{i}$ :

$$
\alpha^{i} \equiv \frac{v_{\Delta c}^{i}}{v_{c}^{i}+v_{\Delta c}^{i}} \in[0,1)
$$

\footnotetext{
${ }^{9}$ Blumkin and Sadka (2007) made a similar assumption. An alternative would be to assume that the individuals recognize their own influence on the public good while treating others' contributions as exogenous (see, e.g., Bergstrom, Blume, and Varian, 1985). This distinction is not of major importance for the qualitative results presented below. If the individuals recognize their own influence on the public good when deciding on their charitable giving, a public goods effect will be added to equation (9), which would reappear in the policy rules for marginal taxation/subsidization of charitable giving (and would contribute to a lower marginal tax or higher marginal subsidy). Except for this modification, all policy rules would take exactly the same form as below.
} 


$$
\beta^{i} \equiv \frac{v_{\Delta g}^{i}}{v_{g}^{i}+v_{\Delta g}^{i}} \in[0,1) .
$$

The degree of consumption positionality, following, e.g., Johansson-Stenman et al. (2002), reflects the share of the marginal utility of consumption arising from an increase in $\Delta c$. Therefore, ${ }^{i}$ can be interpreted as the share of the overall utility gain of an additional dollar spent on consumption that is due to increased relative consumption for an individual of ability-type $i$. The degree of charitable positionality is correspondingly defined as the share of the marginal utility of charitable giving arising from an increase in $\Delta g$. If the charitable giving increases by one dollar (ceteris paribus), the contributor's utility increases due to both the warm-glow effect and the (presumably status-driven) effect of increased relative giving. $\beta^{i}$ reflects the share of the utility gain that is due to increased relative giving for an individual of ability-type $i$.

By the assumptions made above, we have $0 \leq \alpha^{i}<1$ and $0 \leq \beta^{i}<1$. For further use, we also define the average degree of consumption positionality, $\bar{\alpha} \equiv\left(\alpha^{1} n^{1}+\alpha^{2} n^{2}\right) / N$, and the average degree of charitable positionality, $\bar{\beta} \equiv\left(\beta^{1} n^{1}+\beta^{2} n^{2}\right) / N$. Since our model assumes mean value comparisons, the average degree of consumption positionality is interpretable in terms of the marginal positional consumption externality per unit of consumption. Similarly, the average degree of charitable positionality measures the marginal positional giving externality per unit of charitable giving. Quasi-experimental research estimates $\bar{\alpha}$ to be in the 0.2-0.6 range (see, e.g., Johansson-Stenman et al., 2002; Clark and Senik, 2005; Carlsson et al., 2007; and the overview given in Wendner and Goulder, 2008). We are not aware of any empirical estimate of the $\beta \mathrm{s} .{ }^{10}$

\subsection{Constraints Facing the Government}

Irrespective of whether the government is welfarist or paternalist, it faces the same selfselection constraint and resource constraint. We describe these constraints below.

Following convention in the literature on optimal income taxation, the government is able to observe income while individual ability is private information. The government is also able to observe (and thus directly tax or subsidize) charitable giving. We consider a "normal case"

\footnotetext{
${ }^{10}$ Clearly visible goods are likely subject to greater relative concerns (and are thus characterized by a larger degree of positionality) than less visible goods (e.g., Alpizar et al., 2005; Carlsson et al., 2007).
} 
where the government wants to redistribute from the high-ability to the low-ability type. This means that we must add a self-selection constraint that serves to prevent individuals of the high-ability type from mimicking the low-ability type in order to gain from the redistribution. The utility function of the (high-ability) mimicker, denoted by a hat, ${ }^{11}$ is given by

$$
\hat{U}^{2}=\hat{v}^{2}\left(c^{1}, 1-\phi l^{1}, g^{1}, \Delta c^{1}, \Delta g^{1}, G\right)=\hat{u}^{2}\left(c^{1}, 1-\phi l^{1}, g^{1}, \bar{c}, \bar{g}, G\right),
$$

where $\phi \equiv w_{1} / w_{2}$ denotes the relative wage rate that converts labor (and leisure) units of the low-ability type into the corresponding units for the mimicker and $\phi l^{1}$ represents the mimicker's labor supply. The potential mimicker is a high-ability individual who pretends to be a low-ability individual by earning the same income as the low-ability type (i.e., $w^{2} \phi l^{1}=w^{1} l^{1}$ ). Since charitable giving is observable by assumption, whereas ability is not, a potential mimicker will give as much to charity as the true low-ability type. ${ }^{12}$ Thus, if written in terms of the function $u^{2}(\cdot)$ in equation (5), the self-selection constraint is given by

$$
u^{2}\left(c^{2}, z^{2}, g^{2}, \bar{c}, \bar{g}, G\right) \geq \hat{u}^{2}\left(c^{1}, 1-\phi l^{1}, g^{1}, \bar{c}, \bar{g}, G\right) .
$$

The reason (12) applies under both a welfarist and a paternalist government is that the selfselection constraint serves to eliminate the incentive for high-ability individuals to become mimickers. Thus, this constraint must reflect this type's true preferences, regardless of whether the government bases its objective on the individuals' true preferences (as the welfarist government) or laundered preferences (as a paternalist government).

Finally, the economy's resource constraint is given by

$$
\sum_{i=1}^{2} n^{i} w^{i} l^{i}=\sum_{i=1}^{2} n^{i}\left(c^{i}+g^{i}\right)+G^{G o v} .
$$

Equation (13) means that output is used for private consumption and for private and public contributions to the public good.

\footnotetext{
${ }^{11}$ Note that the mimicker and the true high-ability type share a common utility function. The hat symbol just allows us to separate them in a simple way.

12 Thus, the potential mimicking takes place in two dimensions, which are related. For example, in the case where both types have the same leisure separable utility function, according to Definition 1, it is easy to show that the mimicker would choose the same amount of charitable giving as the low-ability type even if this would not be required per se, i.e., in the case where only consumption mimicking would be required.
} 


\section{Optimal Taxation and Public Good Provision under Welfarism}

The social decision problem is formulated as one of deriving a Pareto-efficient allocation by maximizing the utility of the low-ability type subject to a minimum utility level for the highability type. The other constraints are the self-selection and resource constraints given by (12) and (13), respectively.

\subsection{The Welfarist Optimization Problem and First-Order Conditions}

Since the welfarist government fully respects all aspects of consumer preferences (including concerns for relative consumption and relative charitable giving) and forms the social objective thereupon, the socially optimal resource allocation solves the following problem:

$$
\begin{aligned}
\cos _{c^{1}, c^{2}, l^{1}, l^{2}, g^{1}, g^{2}, G^{G o v}} L & =u^{1}\left(c^{1}, z^{1}, g^{1}, \bar{c}, \bar{g}, G\right)+\delta\left[u^{2}\left(c^{2}, z^{2}, g^{2}, \bar{c}, \bar{g}, G\right)-\bar{U}^{2}\right] \\
& +\gamma\left[\sum_{i=1}^{2} n^{i}\left(w^{i} l^{i}-c^{i}-g^{i}\right)-G^{G o v}\right] \\
& +\lambda\left[u^{2}\left(c^{2}, z^{2}, g^{2}, \bar{c}, \bar{g}, G\right)-\hat{u}^{2}\left(c^{1}, 1-\phi l^{1}, g^{1}, \bar{c}, \bar{g}, G\right)\right] \\
& +\omega_{G^{G o v}} G^{G o v}+\omega_{g^{1}} g^{1}+\omega_{g^{2}} g^{2}
\end{aligned}
$$

where $\bar{U}^{2}$ specifies a fixed utility level for high-ability individuals. The Lagrange multipliers $\delta, \gamma, \lambda$ refer to the minimum utility restriction, the resource constraint, and the self-selection constraint, respectively, while the Lagrange multipliers $\omega_{G^{G o v}}, \omega_{g^{1}}, \omega_{g^{2}}$ are associated with the non-negativity constraints on the contributions to the public good by the government and by the low-ability and high-ability individuals, respectively. In contrast to individual households, the government takes the positional externalities - as arising from $\bar{c}$ and $\bar{g}$ - into account. The social first-order conditions can then be written as

$$
\begin{gathered}
L_{c^{1}}=u_{c}^{1}-\lambda \hat{u}_{c}^{2}-\gamma n^{1}+\frac{n^{1}}{N} L_{\bar{c}}=0 \\
L_{c^{2}}=(\delta+\lambda) u_{c}^{2}-\gamma n^{2}+\frac{n^{2}}{N} L_{\bar{c}}=0 \\
L_{l^{1}}=-u_{z}^{1}+\lambda \phi \hat{u}_{z}^{2}+\gamma n^{1} w^{1}=0 \\
L_{l^{2}}=-(\delta+\lambda) u_{z}^{2}+\gamma n^{2} w^{2}=0 \\
L_{g^{1}}=u_{g}^{1}-\lambda \hat{u}_{g}^{2}+u_{G}^{1}(1-\mu) n^{1}+(\delta+\lambda) u_{G}^{2}(1-\mu) n^{1}-\lambda \hat{u}_{G}^{2}(1-\mu) n^{1}-\gamma n^{1}+\omega_{g^{1}}+\frac{n^{1}}{N} L_{\bar{g}}=0 \\
L_{g^{2}}=(\delta+\lambda) u_{g}^{2}+u_{G}^{1}(1-\mu) n^{2}+(\delta+\lambda) u_{G}^{2}(1-\mu) n^{2}-\lambda \hat{u}_{G}^{2}(1-\mu) n^{2}-\gamma n^{2}+\omega_{g^{2}}+\frac{n^{2}}{N} L_{\bar{g}}=0 \\
L_{G^{G o v}}=u_{G}^{1}+(\delta+\lambda) u_{G}^{2}-\lambda \hat{u}_{G}^{2}+\omega_{G^{G o v}}-\gamma=0
\end{gathered}
$$


In equations (15) and (16), $L_{\bar{c}}$ denotes the partial welfare effect of increased reference consumption, $\bar{c}$, given by

$$
L_{\bar{c}}=u_{\bar{c}}^{1}+(\delta+\lambda) u_{\bar{c}}^{2}-\lambda \hat{u}_{\bar{c}}^{2} .
$$

Similarly, $L_{\bar{g}}$ denotes the partial welfare effect of increased reference giving, $\bar{g}$, and takes the following form:

$$
L_{\bar{g}}=u_{\bar{g}}^{1}+(\delta+\lambda) u_{\bar{g}}^{2}-\lambda \hat{u}_{\bar{g}}^{2} .
$$

The right-hand side of equation (22) is ambiguous in sign, since an increase in $\bar{c}$ reduces the utility for the true ability types (which contributes to lower welfare) and for the mimicker (which contributes to higher welfare). The interpretation of equation (23) is analogous. Note that for an interior solution in all choice variables, none of the non-negativity constraints would bind, implying that $\omega_{G^{G o v}}=\omega_{g^{1}}=\omega_{g^{2}}=0$.

\subsection{Optimal Marginal Income Tax Rates and Public Good Provision}

In this subsection, we present the policy rules for marginal income taxation and public good provision, respectively, whereas the marginal tax treatment of charitable giving will be analyzed in subsections 4.3 and 4.4. Let $M R S_{z, c}^{i}=u_{z}^{i} / u_{c}^{i}$ denote the private marginal rate of substitution between leisure and private consumption and $M R S_{G, c}^{i}=u_{G}^{i} / u_{c}^{i}$ the private marginal rate of substitution between the public good and private consumption for ability-type $i$. Let us also introduce indicators for the differences in the degree of consumption positionality between the mimicker and the low-ability type, $\alpha^{d} \equiv\left(\hat{\alpha}^{2}-\alpha^{1}\right) \lambda \hat{u}_{c}^{2} /(\gamma N)$, and in the degree of charitable positionality between the mimicker and the low-ability type, $\beta^{d} \equiv\left(\hat{\beta}^{2}-\beta^{1}\right) \lambda \hat{u}_{g}^{2} /(\gamma N)$. Note that $\alpha^{d}$ and $\beta^{d}$ are proportional to the Lagrange multiplier of the self-selection constraint, $\lambda$. Therefore, these components are due to the second-best assumption of asymmetric information (and would vanish in a first-best setting where individual ability is observable to the government).

To simplify the presentation of the results, we will use the short notation

$$
\begin{aligned}
\tau^{1} & =\frac{\lambda \hat{u}_{c}^{2}}{\gamma n^{1} w^{1}}\left[M R S_{z, c}^{1}-\phi M \hat{R} S_{z, c}^{2}\right] \\
\tau^{2} & =0
\end{aligned}
$$

to summarize the policy rules for marginal income taxation that would apply in a standard model without any relative concerns. The expressions for $\tau^{1}$ and $\tau^{2}$ coincide with the marginal income tax policy derived in a standard two-type model by Stiglitz (1982). In our 
model, these policy rules would apply if the government (erroneously) were treating the levels of reference consumption and reference giving as exogenous. Proposition 1 summarizes the policy rules for marginal income taxation and public good provision.

Proposition 1. The optimal marginal income tax rates are given as (for $i=1,2)$

$$
T_{w l}^{i}\left(w^{i} l^{i}, g^{i}\right)=\tau^{i}+\left[1-\tau^{i}\right] \bar{\alpha}-\left[1-\tau^{i}\right][1-\bar{\alpha}] \frac{\alpha^{d}}{1-\alpha^{d}},
$$

while the optimal provision of the public good satisfies the following policy rule if $G^{\text {Gov }}>0$ :

$$
\sum_{i} n^{i} M R S_{G, c}^{i} \frac{1-\alpha^{d}}{1-\bar{\alpha}}+\frac{\lambda \hat{u}_{c}^{2}}{\gamma}\left[M R S_{G, c}^{1}-M \hat{R} S_{G, c}^{2}\right]=1 .
$$

Proof: See the Appendix.

These policy rules for marginal income taxation and public good provision are identical to the corresponding policy rules derived by Aronsson and Johansson-Stenman (2008) in a model with relative consumption concerns (as here) but without charitable giving. This is an important separation result and implies that the policy rules for marginal income taxation and public good provision can be expressed in the same general forms as in the absence of private contributions to the public good. The intuitive reason equations (24) and (25) apply here as well is that the government can control charitable giving through a direct tax instrument, meaning that charitable giving will not change the policy rule for marginal income taxation or the rule for public provision of public goods. ${ }^{13}$

We can see from equation (24) that the marginal income tax rates are decomposable into three distinct policy incentives: (1) relaxation of the self-selection constraint by exploiting that the mimicker and the low-ability type differ in their marginal valuation of leisure time (the first term); (2) correction for the positional consumption externality, which depends on the average degree of consumption positionality, $\bar{\alpha}$ (the second term); and (3) relaxation of the selfselection constraint by exploiting that a mimicker and the low-ability type may differ in terms of degree of consumption positionality, as reflected by $\alpha^{d}$ (the third term). Similarly, equation (25) shows that the relative consumption concerns enter the policy rule for public good provision through a single multiplier, $\left(1-\alpha^{d}\right) /(1-\bar{\alpha})$, attached to the sum of the

\footnotetext{
${ }^{13}$ See Aronsson, Johansson-Stenman, and Wendner (2018) for a case (without public goods) where the government lacks a direct instrument to control charitable giving, and where the policy rules for marginal income taxation are modified accordingly.
} 
marginal willingness to pay for the public good. If $\bar{\alpha}=\alpha^{d}=0$, the policy rule for public good provision reduces to read

$$
\sum_{i} n^{i} M R S_{G, c}^{i}+\frac{\lambda \hat{u}_{c}^{2}}{\gamma}\left[M R S_{G, c}^{1}-M \hat{R} S_{G, c}^{2}\right]=1 .
$$

Equation (25a) coincides with the second-best analogue to the Samuelson condition derived by Boadway and Keen (1993) in a model where people do not care about their relative consumption or relative giving. Yet, note that equation (25a) would still apply when people care about their relative charitable giving, as long as they do not care about their relative consumption. Returning to equation (25), we can see that the positional consumption externality (as measured by $\bar{\alpha}$ ) works to scale up the marginal social benefit of public good provision. In turn, this effect is either counteracted or reinforced by $\alpha^{d}$ (which reflects the difference in the degree of consumption positionality between a mimicker and the low-ability type). If $\alpha^{d}>0$, the government can relax the self-selection constraint through a policyinduced increase in private consumption, which results in a smaller public good, and vice versa if $\alpha^{d}<0$. The details behind these mechanisms are well understood and discussed at length in Aronsson and Johansson-Stenman (2008), and will not be further discussed here.

It is worth noting that if we assume leisure separability according to Definition 1 , then the policy rules in Proposition 1 would be simplified as follows:

Corollary 1. If the utility functions are leisure separable, then the optimal marginal income tax rates are given as (for $i=1,2)$

$$
T_{w l}^{i}\left(w^{i} l^{i}, g^{i}\right)=\tau^{i}+\left[1-\tau^{i}\right] \bar{\alpha},
$$

while the optimal provision of the public good satisfies the following policy rule if $G^{\text {Gov }}>0$ :

$$
\sum_{i} n^{i} \frac{M R S_{G, c}^{i}}{1-\bar{\alpha}}+\frac{\lambda \hat{u}_{c}^{2}}{\gamma}\left[M R S_{G, c}^{1}-M \hat{R} S_{G, c}^{2}\right]=1
$$

The intuition behind equations (26) and (27) is that $\alpha^{d}=0$ under leisure separability. It is also worth analyzing a more restrictive version of the leisure separable utility function, resembling the one in Boadway and Keen (1993). Adapted to our model with charitable giving, this utility function can be written as $U^{i}=V^{i}\left(k\left(c^{i}, g^{i}, \bar{c}, \bar{g}, G\right), z^{i}\right)$, where $G$ only shows up in the sub-utility function $k$. This case means that the marginal rate of substitution 
between the public and the private good is also unaffected by leisure, which in turn implies that equation (27) can be simplified even further, as follows:

$$
\sum_{i} n^{i} \frac{M R S_{G, c}^{i}}{1-\bar{\alpha}}=1
$$

Clearly, in the special (and conventional) case with no consumption positionality $(\bar{\alpha}=0)$, we obtain the standard Samuelson (1954) condition

$$
\sum_{i} n^{i} M R S_{G, c}^{i}=1 .
$$

Thus, we have generalized the important result by Boadway and Keen (1993) that the firstbest Samuelson condition for public good provision is optimal under leisure separability to a setting that also involves charitable giving, including when it is partly driven by a status motive (such that $\bar{\beta}>0$ ).

\subsection{Marginal Taxation of Charitable Giving under Interior Solutions}

We will now turn to the marginal taxation/subsidization of charitable giving, i.e., the main focus of the paper. We start with the case of interior solutions where $g^{1}, g^{2}$, and $G^{G o v}$ are all positive at the social optimum, meaning that $\omega_{g^{1}}=\omega_{g^{2}}=\omega_{G^{G o v}}=0$. Let

$$
M R S_{g, c}^{i}=\frac{u_{g}^{i}}{u_{c}^{i}}=\frac{v_{g}^{i}+v_{\Delta g}^{i}}{v_{c}^{i}+v_{\Delta c}^{i}} \text { for } i=1,2, \text { and } M \hat{R} S_{g, c}^{2}=\frac{\hat{u}_{g}^{2}}{\hat{u}_{c}^{2}}=\frac{\hat{v}_{g}^{2}+\hat{v}_{\Delta g}^{2}}{\hat{v}_{c}^{2}+\hat{v}_{\Delta c}^{2}}
$$

denote the private marginal rate of substitution between charitable giving and private consumption for ability-type $i$ and the mimicker, respectively. The marginal tax/subsidy on charitable giving can then be characterized as follows:

Proposition 2. If $G^{G o v}>0$ at the social optimum, and if both ability types contribute to charity, the optimal marginal tax/subsidy rates on charitable giving can be written as

$$
\begin{gathered}
T_{g}^{1}=\frac{\lambda \hat{u}_{c}^{2}}{\gamma n^{1}}\left(M \hat{R} S_{g, c}^{2}-M R S_{g, c}^{1}\right) \frac{1-\bar{\alpha}}{1-\alpha^{d}}+\frac{1-\bar{\alpha}}{1-\bar{\beta}} \frac{\mu-\beta^{d}}{1-\alpha^{d}}-1, \\
T_{g}^{2}=\frac{1-\bar{\alpha}}{1-\bar{\beta}} \frac{\mu-\beta^{d}}{1-\alpha^{d}}-1 .
\end{gathered}
$$

Proof: See the Appendix.

To simplify the interpretation of Proposition 2, consider first the special case of leisure separability according to Definition $1 .^{14}$

\footnotetext{
${ }^{14}$ It is easy to show that the same choice rule follows in a first-best resource allocation, which coincides with the special case of our model where the self-selection constraint does not bind (i.e., $\lambda=0$ ).
} 
Corollary 2. If, in addition to the conditions in Proposition 2, the utility functions are leisure separable, then the optimal marginal tax/subsidy rates on charitable giving can be written as (for $i=1,2$ )

$$
T_{g}^{i}=\frac{1-\bar{\alpha}}{1-\bar{\beta}} \mu-1
$$

Equation (32) means that the marginal tax/subsidy attached to charitable giving depends on the two positional externalities, measured by the average degrees of consumption positionality and charitable positionality, and the transaction cost attached to charitable giving, $\mu$. In the absence of any transaction cost, i.e., if $\mu=0$, equation (32) takes the following simple form:

$$
T_{g}^{i}=-1 \text {, }
$$

implying a marginal subsidy rate of 100 percent. This extreme result may seem surprising at first thought. In order to provide intuition, let us first note that equation (32) also holds in a first-best resource allocation, where the self-selection constraint does not bind. In this case, and if $\mu=0$, an individual of ability-type $i$ would on the margin obtain the same utility from giving one additional dollar to charity (through warm-glow and status concerns) as if she instead would consume it herself. Hence, she is indifferent between these alternatives. Yet, the government, representing society, is not indifferent. If the individual gives one additional dollar to charity, the size of the public good increases, and the size of this increase is exactly equal to one dollar, i.e., the same size as the additional donation itself. In other words, there is a positive fiscal externality attached to voluntary contributions, where the external benefit is as large as the contribution itself, implying an optimal first-best externality-correcting subsidy rate of 100 percent. ${ }^{15}$ This mechanism corresponds to the externality motive for subsidizing

\footnotetext{
${ }^{15}$ It is straightforward to show this result algebraically when $\lambda=\mu=0$, in which case the social first-order conditions for $g^{1}$ and $g^{2}$ in equation (19) and (20) reduce to read

$$
\begin{aligned}
& L_{g^{1}}=u_{g}^{1}+\frac{n^{1}}{N} L_{\bar{g}}=0 \\
& L_{g^{2}}=\delta u_{g}^{2}+\frac{n^{2}}{N} L_{\bar{g}}=0 .
\end{aligned}
$$

To maximize the social welfare, the private contributions to charity should be set at a level where the social marginal utility of warm glow (i.e., the private marginal utility net of the externality caused by charitable giving positionality) is zero. This means that the above equations are satisfied simultaneously at the social optimum if $v_{g}^{1}=v_{g}^{2}=0$ (if such an interior optimum exists), implying that equation (9) can be written as
} 
charity in the optimal linear income tax model of Saez (2004). Another - albeit equivalent interpretation of equation (33) is that charitable giving leads to higher utility for the donor without influencing the economy's resource constraint. Yet, for this extreme result to be possible, it must be the case that the marginal warm glow of giving approaches zero at a certain level of giving; in other words, at a sufficiently high level of charitable giving the individual is indifferent between giving and not giving more, even though the marginal cost of charitable giving is zero. ${ }^{16}$

Why does equation (33) continue to apply in a second-best setting under leisure separability, if the transaction cost is zero? The crude intuition is that the choice between giving and consuming one additional dollar per se leaves the marginal rate of substitution between leisure and consumption unaffected, and thus, the equity-efficiency tradeoff is more efficiently dealt with solely through the marginal income taxes. This result resembles some of the insights emanating from earlier research on optimal nonlinear income taxation under leisure separability, such as the finding by Atkinson and Stiglitz (1976) that consumption taxes should not be differentiated across commodities, and the conclusion by Boadway and Keen (1993) that one should rely on the first-best Samuelson condition for public good provision.

This extreme policy should clearly be modified if $\mu>0$, which can be seen from equation (32). This case means that voluntary contributions necessitate more resources than public provision, ceteris paribus, or that such provision implies a lower social benefit per dollar, which motivates a less generous tax treatment of voluntary contributions. Note also that the effect of the transaction cost on the marginal tax/subsidy on charitable giving depends on the two externalities involved, as represented by the average degrees of consumption positionality and charitable positionality. The higher the degree of charitable positionality, $\bar{\beta}$, the lower the marginal subsidy, or the higher the marginal tax, on charitable contributions will be. This

$$
\frac{u_{g}^{i}}{u_{c}^{i}}=\frac{v_{g}^{i}}{v_{c}^{i}} \frac{1-\alpha^{i}}{1-\beta^{i}}=1+T_{g}^{i}=0 .
$$

\footnotetext{
${ }^{16}$ If, on the other hand, utility were monotonically increasing in charitable giving, then a $100 \%$ subsidy rate would mean that there is no role left for public provision of the public good. But this contradicts the assumption of an interior solution in public provision. Instead, we should then apply the corresponding choice rule given by Proposition 3 below. This, in turn, would preclude a 100\% subsidy rate.
} 
result is intuitive since $\bar{\beta}$ reflects the marginal positional-giving externality per unit of contribution, implying that a higher $\bar{\beta}$ weakens the policy incentive to support charitable giving. By analogy, a higher $\bar{\alpha}$ leads to an increase in the marginal subsidy, or decrease in the marginal tax, on charitable giving. The reason is, of course, that $\bar{\alpha}$ measures the positional consumption externality per unit of consumption, and thus, an increase in $\bar{\alpha}$ would motivate a policy-induced switch from consumption to charitable contributions, ceteris paribus. Therefore, whereas $\mu$ can be thought of as the private marginal resource cost of charitable contributions, $\mu(1-\bar{\alpha}) /(1-\bar{\beta})$ is interpretable in terms of the corresponding social marginal resource cost. Another important insight from Corollary 2 is that in the special case where the average degrees of consumption positionality and charitable positionality are equal, such that $\bar{\alpha}=\bar{\beta}$, all relative concerns cancel and the expression for the optimal marginal tax rate on charitable giving reduces to

$$
T_{g}^{i}=\mu-1
$$

Yet, based on equation (32), it is worth noting that nothing prevents the optimal marginal tax on charitable giving from being positive. In fact, it may in principle even be quantitatively large. $^{17}$

Let us now return to the general non-separable case represented by equations (30) and (31) in Proposition 2. Two additional effects of second-best type arise here compared with equation (32). First, the government may relax the self-selection constraint by exploiting whether the mimicker's marginal willingness to pay for charitable contributions exceeds, or falls short of, a low-ability individual's marginal willingness to pay. This effect modifies the marginal tax treatment of charitable giving by low-ability individuals, and is represented by the first term on the right-hand side of equation (30). If the mimicker is willing to pay more (less) than the low-ability type for a marginal contribution to charity, such that $M \hat{R} S_{g, c}^{2}>(<) M R S_{g, c}^{1}$, the government may relax the self-selection constraint through a policy-induced decrease (increase) in the low-ability type's contribution to charity. Finally, note that this policy incentive has nothing to do with relative concerns per se; it would be present also in a model where $\alpha^{i}=\beta^{i}=0$ for all $i$.

\footnotetext{
${ }^{17}$ This would be the case if $\bar{\beta}$ is substantially larger than $\bar{\alpha}$, and if $\mu$ is large. For example, if $\bar{\alpha}=0.2$, $\bar{\beta}=0.7$, and $\mu=0.5$, then $T_{g}^{i}=0.33$, i.e., an optimal marginal tax rate on charitable giving of 33 percent.
} 
Second, the government may also relax the self-selection constraint by exploiting possible differences in the degrees of (consumption and charitable) positionality between the mimicker and the low-ability type. If the mimicker is more giving-positional than the low-ability type such that $\beta^{d} \equiv\left(\hat{\beta}^{2}-\beta^{1}\right) \lambda \hat{u}_{g}^{2} /(\gamma N)>0$, it follows that the mimicker is hurt more than the low-ability type by an increase in the positional charitable-giving externality. In turn, this provides an incentive for the government to relax the self-selection constraint through more favorable marginal tax treatment of charitable contributions, i.e., through a higher marginal subsidy or lower marginal tax. An analogous argument for a less favorable marginal tax treatment of charitable giving would follow if the low-ability type were hurt more than the mimicker by an increase in the positional-giving externality, i.e., if $\beta^{d}<0$. The related component $\alpha^{d} \equiv\left(\hat{\alpha}^{2}-\alpha^{1}\right) \lambda \hat{u}_{c}^{2} /(\gamma N)$ is interpretable in the same general way. If the mimicker is more consumption-positional than the low-ability type, i.e., if $\alpha^{d}>0$, then she will be hurt more than the low-ability type by an increase in the positional consumption externality. This suggests that increased private consumption and thus reduced charitable contributions lead to higher welfare through a relaxation of the self-selection constraint, ceteris paribus, and motivate higher marginal taxation (or reduced marginal subsidization) of private charitable contributions. ${ }^{18}$ The analogous argument for more favorable marginal tax treatment of charitable contributions follows if $\alpha^{d}<0$.

\subsection{When Should Charitable Giving Be Subsidized or Taxed under Interior Solutions?}

In the previous subsection, we analyzed the policy rules underlying the marginal tax treatment of charitable giving under interior solutions. In such a context, it is of particular interest to address the conditions under which charitable giving should be subsidized at the margin (such that the optimal marginal tax rate is negative) and when it should be taxed. These conditions follow immediately from Proposition 2.

Corollary 3. Given an interior solution for the contribution by each ability type and for the government, charitable giving should be subsidized (taxed) at the margin for the low-ability type iff

$$
\mu<(>) \beta^{d}+\frac{(1-\bar{\beta})\left(1-\alpha^{d}\right)}{1-\bar{\alpha}}-(1-\bar{\beta}) \frac{\lambda \hat{u}_{c}^{2}}{\gamma n^{1}}\left(M \hat{R} S_{g, c}^{2}-M R S_{g, c}^{1}\right)
$$

\footnotetext{
${ }^{18}$ Strictly speaking, this argument presupposes that $\mu-\beta^{d}>0$.
} 
and for the high-ability type iff

$$
\mu<(>) \beta^{d}+\frac{(1-\bar{\beta})\left(1-\alpha^{d}\right)}{1-\bar{\alpha}} .
$$

The mechanisms involved are of course the same as in the optimal marginal tax formulas presented above. Therefore, leisure separability will imply a considerable simplification here as well:

Corollary 4. If, in addition to the conditions in Corollary 3, the utility functions are leisure separable, then charitable giving should for each ability type be subsidized (taxed) at the margin iff

$$
\mu<(>) \frac{1-\bar{\beta}}{1-\bar{\alpha}}
$$

Given the leisure-separable setting, we can immediately observe that quite specific assumptions are required for charitable giving to be taxed in optimum. Indeed, sufficient (but not necessary) conditions for charitable giving to be subsidized at the margin are that either $\mu=0, \bar{\beta}=0$ or $\bar{\alpha} \geq \bar{\beta}$. Correspondingly, necessary (but not sufficient) conditions for positive marginal tax rates on charitable giving are that $\mu>0, \bar{\beta}>0$, and $\bar{\beta} \geq \bar{\alpha}$. The striking simplicity of condition (37), despite the complexity of the underlying decision problem, is illustrated in Figure 1 below.

The optimal marginal tax on charitable giving for each ability type is equal to zero on each of the lines in the figure, which in turn shows a combination of positional externalities and transaction costs of charitable giving. For instance, the marginal tax (or subsidy) is equal to zero for the combination $\bar{\alpha}=0.2, \bar{\beta}=0.8$, and $\mu=0.25$. Moreover, it is optimal with a marginal subsidy on charitable giving southeast of each line, and correspondingly optimal with a marginal tax on charitable giving northwest of each line. 
Figure 1. Marginal Taxation or Subsidization of Charitable Giving

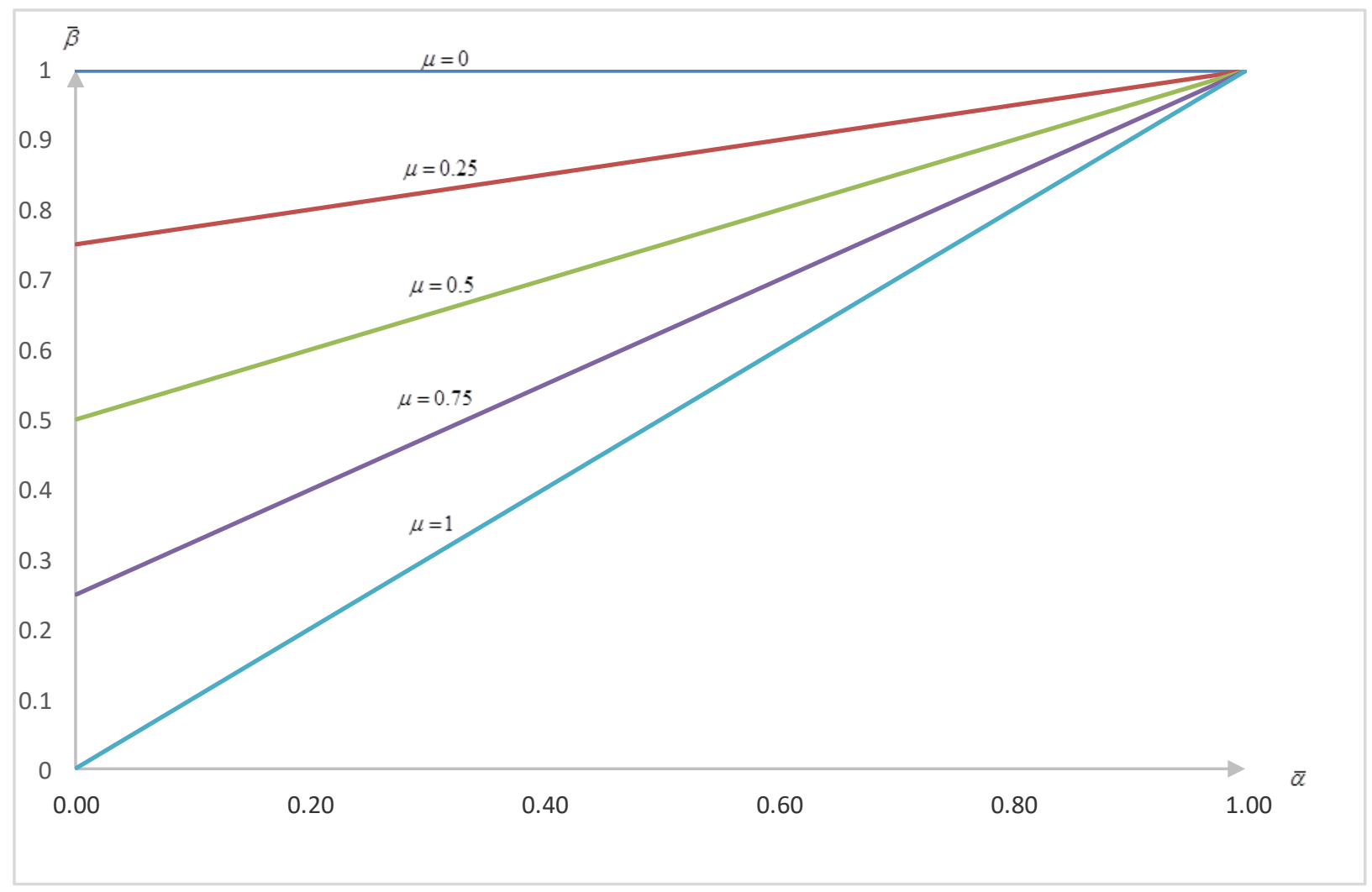

Note. Each line represents a combination of average degrees of consumption positionality, $\bar{\alpha}$, charitable giving positionality, $\bar{\beta}$, and the transaction cost of charitable giving, $\mu$, such that the marginal tax on charitable giving equals zero for both ability types, given interior solutions and leisure separability.

\subsection{Optimal Taxation and Public Good Provision when Corner Solutions Are Optimal}

The marginal tax treatment of charitable giving in Proposition 2 presupposes that none of the non-negativity constraints bind, i.e., $\omega_{g^{1}}=\omega_{g^{2}}=\omega_{G^{G o v}}=0$. This is consistent with $g^{1}>0$, $g^{2}>0$, and $G^{G o v}>0$ at the social optimum, which means that it is socially desirable that both ability types contribute to the public good via charitable giving and that the government also contributes directly to the public good (by raising revenue to finance the necessary public expenditure). However, corner solutions play a potentially very important role in our model. The reason is, of course, that public good provision per se does not require that $g^{1}, g^{2}$, and $G^{G o v}$ are all positive, and none of these quantities can be negative. It is thus also relevant to analyze corner solutions where one or more of these variables are zero at the social optimum.

Let us start with the policy rules for marginal income taxation and public good provision in Proposition 1, i.e., equations (30) and (31). As described in subsection 4.2, these policy rules 
do not depend on whether individuals contribute voluntarily to the public good and will thus continue to hold also in cases where individuals of one or both ability types do not contribute anything to charity. Moreover, the policy rules for marginal income taxation will continue to hold also in the case where the government does not contribute to the public good.

Consider next the question of how the optimal marginal tax (subsidy) rule for charitable giving changes under corner solutions. This question can be divided into two sub-questions: First, how will the marginal tax rule for charitable giving by a certain ability type change when the optimal contribution by the same type is zero? Second, how will the marginal tax rule for charitable giving implemented for a certain ability type change when the optimal contribution by the other type, or by the government, is zero?

We start with the first sub-question by analyzing the conditions under which corner solutions (and indirectly also the conditions under which interior solutions) for charitable giving arise. It is natural to express these conditions in terms of a critical level for the marginal rate of substitution between charitable giving and private consumption. A corner solution follows when it is optimal from a social point of view that the individual does not contribute anything more, starting from a situation where the contribution is zero. One can then show that the critical level in terms of the marginal rate of substitution between charitable giving and private consumption is given as follows for the low-ability type:

$$
\left.M R S_{g, c}^{1}\right|_{g^{1}=0} \leq\left.\left(\frac{\lambda \hat{u}_{c}^{2}}{\gamma n^{1}}\left(M \hat{R} S_{g, c}^{2}-M R S_{g, c}^{1}\right) \frac{1-\bar{\alpha}}{1-\alpha^{d}}+\frac{1-\bar{\alpha}}{1-\bar{\beta}} \frac{\mu-\beta^{d}}{1-\alpha^{d}}\right)\right|_{g^{1}=0} .
$$

Thus, if the individual's marginal rate of substitution is less than or equal to the expression on the right-hand side evaluated at $g^{1}=0$, then a corner solution where the individual does not contribute to charity is socially optimal. A strict inequality is associated with a binding nonnegativity constraint for $g^{1}$, such that the corresponding Lagrange multiplier in equation (19) is strictly positive, i.e., $\omega_{g^{1}}>0$. Now, how can we implement this condition through tax policy? By combining equation (38) with the private optimum conditions in equation (9), it follows that we should implement a marginal tax (positive or negative) on contributions such that

$$
T_{g}^{1} \geq\left.\left(\frac{\lambda \hat{u}_{c}^{2}}{\gamma n^{1}}\left(M \hat{R} S_{g, c}^{2}-M R S_{g, c}^{1}\right) \frac{1-\bar{\alpha}}{1-\alpha^{d}}+\frac{1-\bar{\alpha}}{1-\bar{\beta}} \frac{\mu-\beta^{d}}{1-\alpha^{d}}\right)\right|_{g^{1}=0}-1 .
$$

In the special case of leisure separability, equation (39) reduces to read 


$$
T_{g}^{1} \geq\left.\left(\frac{1-\bar{\alpha}}{1-\bar{\beta}} \mu\right)\right|_{g^{1}=0}-1 .
$$

That is, we need at least the level of marginal taxation implied by the right-hand side of equation (39) (or [40] in the leisure-separable case) to ensure that it is not optimal for lowability individuals to contribute to charity. Note that the algebraic expressions on the righthand side of inequalities (39) and (40) are analogous to the corresponding expressions in Proposition 2 and Corollary 2, i.e., the right-hand side of equations (30) and (32), with the only difference being that they are here evaluated at $g^{1}=0 .{ }^{19}$

The same reasoning holds for the contributions made by high-ability individuals. To ensure that the high-ability type does not contribute to charity - if such an outcome is socially desirable - the marginal tax rate should satisfy the following condition:

$$
T_{g}^{2} \geq\left.\left(\frac{1-\bar{\alpha}}{1-\bar{\beta}} \frac{\mu-\beta^{d}}{1-\alpha^{d}}\right)\right|_{g^{2}=0}-1,
$$

where a strict inequality is associated with a binding non-negativity constraint for $g^{2}$, such that $\omega_{g^{2}}>0$ in equation (20). The right-hand side of inequality (41) takes the same form as that of equation (31), except that (41) is evaluated at $g^{2}=0$. A simplified expression similar to (40) would of course hold under leisure separability, i.e.,

$$
T_{g}^{2} \geq\left.\left(\frac{1-\bar{\alpha}}{1-\bar{\beta}} \mu\right)\right|_{g^{2}=0}-1
$$

Let us now turn to the second sub-question and start with the optimal tax treatment of charitable giving when the government does not contribute to the public good, i.e., where $G^{G o v}=0$ at the social optimum. This case arises if the voluntary contributions to charity, $g^{1}$ and $g^{2}$, are large enough to imply

$$
\left.\left(\sum_{i} n^{i} M R S_{G, c}^{i} \frac{1-\alpha^{d}}{1-\bar{\alpha}}+\frac{\lambda \hat{u}_{c}^{2}}{\gamma}\left[M R S_{G, c}^{1}-M \hat{R} S_{G, c}^{2}\right]\right)\right|_{G^{G o v}=0} \leq 1,
$$

\footnotetext{
${ }^{19}$ If a corner solution is optimal, and if there is a negative relationship between the marginal tax rate and the contribution to charity, this means that the marginal tax rates corresponding to the infeasible, imagined negative contributions implied by equations (30) and (32) are larger than the right-hand side of inequalities (39) and (40), respectively. This suggests that the marginal tax rates implied by equations (30) and (32) will give the desired corner solution in terms of charitable giving. However, these marginal tax rates constitute sufficient, not necessary, conditions for implementing this corner solution, since $g^{1}=0$ will also follow for lower marginal tax rates, as long as these are high enough according to inequalities (39) and (40).
} 
where a strict inequality is associated with a binding non-negativity constraint for $G^{G o v}$, such that $\omega_{G^{G o v}}>0$ in equation (21), i.e., an incremental contribution by the government would provide less social benefits than social costs. Thus, when the weak inequality (42) is satisfied, it is optimal for the government not to contribute anything at all to the public good. To simplify the presentation of the results, we introduce the following short notation for the social net marginal cost $(S N M C)$ of providing additional public goods for the government at $G^{G o v}=0$ :

$$
\operatorname{SNMC}\left(G^{G o v} \mid G^{G o v}=0\right)=1-\left.\left(\sum_{i} n^{i} \operatorname{MRS}_{G, c}^{i} \frac{1-\alpha^{d}}{1-\bar{\alpha}}+\frac{\lambda \hat{u}_{c}^{2}}{\gamma}\left[M R S_{G, c}^{1}-M \hat{R}_{G, c}^{2}\right]\right)\right|_{G^{G o v}=0} .
$$

Note that the SNMC of providing the public good, evaluated at the social optimum, is equal to zero under an interior optimal solution. But under a corner solution for the governmental contribution, we have $\operatorname{SNMC}\left(G^{G o v} \mid G^{G o v}=0\right) \geq 0$. As such, there is overprovision of the public good at $G^{G o v}=0$, which in turn constitutes a motive for taxing charitable giving at the margin. This will be described in more detail in Proposition 3 below.

Another (and quite plausible) corner solution refers to the case where one of the types, say the low-ability type, should not contribute to charity, while contributions by the high-ability type are still socially desirable. Compared with the policy rules presented in Proposition 2, it is straightforward to show that this case implies a lower welfare cost of the positional-giving externality, ceteris paribus. This provides an incentive for the government to reduce the marginal tax on charitable giving by the high-ability type.

We are now ready to present the corresponding marginal tax rules for charitable giving in Proposition 3.

Proposition 3. (i) If $G^{G o v}=0, g^{1}>0$, and $g^{2}>0$ at the social optimum, the policy rules for marginal taxation of charitable giving can be written as

$$
\begin{gathered}
T_{g}^{1}=\frac{\lambda \hat{u}_{c}^{2}}{\gamma n^{1}}\left(M \hat{R} S_{g, c}^{2}-M R S_{g, c}^{1}\right) \frac{1-\bar{\alpha}}{1-\alpha^{d}}+\frac{1-\bar{\alpha}}{1-\bar{\beta}} \frac{\mu+(1-\mu) S N M C\left(G^{G o v} \mid G^{G o v}=0\right)-\beta^{d}}{1-\alpha^{d}}-1, \\
T_{g}^{2}=\frac{1-\bar{\alpha}}{1-\bar{\beta}} \frac{\mu+(1-\mu) S N M C\left(G^{G o v} \mid G^{G o v}=0\right)-\beta^{d}}{1-\alpha^{d}}-1
\end{gathered}
$$


(ii) If $g^{1}=0, g^{2}>0$, and $G^{G o v}>0,{ }^{20}$ the policy rules for marginal taxation of charitable giving by high-ability individuals can be written as

$$
T_{g}^{2}=\frac{1-\bar{\alpha}}{1-\bar{\beta}} \frac{\mu-\beta^{1} \omega_{g^{1}} /(\gamma N)-\beta^{d}}{1-\alpha^{d}}-1 .
$$

The proof of Proposition 3 is analogous to the proof of Proposition 2. Under leisure separability, these policy rules take a simpler form (as before), which we describe in Corollary 5.

Corollary 5. Under leisure separability, the policy rules for marginal taxation of charitable giving can be written as follows: (i) If $G^{G o v}=0, g^{1}>0$, and $g^{2}>0$ at the social optimum, then (for $i=1,2)$

$$
T_{g}^{i}=\frac{1-\bar{\alpha}}{1-\bar{\beta}}\left[\mu+(1-\mu) \operatorname{SNMC}\left(G^{G o v} \mid G^{G o v}=0\right)\right]-1 .
$$

(ii) If $g^{j}=0$ and $G^{G o v}>0$, then (for $i=1,2, i \neq j$ )

$$
T_{g}^{i}=\frac{1-\bar{\alpha}}{1-\bar{\beta}}\left[\mu-\frac{\beta^{j} \omega_{g^{j}}}{\gamma N}\right]-1 .
$$

Compared with Proposition 2 and Corollary 2, one additional term appears on the right-hand side of equations (43)-(44) and (46), reflecting the net social marginal cost of public good provision. Thus, this additional incentive works to increase the marginal tax on charitable giving. ${ }^{21}$ To see this more clearly, consider the special case of equation (46) where $\bar{\alpha}=\bar{\beta}$ and $\mu=0$, implying $T_{g}^{i}=\operatorname{SNMC}\left(G^{G o v} \mid G^{G o v}=0\right)-1$. The intuition is that the government would have liked to be able to provide a negative amount of the public good (and receive a corresponding compensation), but cannot due to the non-negativity constraint. A lower marginal subsidy leads to less charitable giving and thus reduces the public good to a level closer to that ideally preferred by the government. The multiplier $1-\mu$ in equations (43)-(44) and (46) arises because the transaction cost reduces the effectiveness of taxation of charitable giving as a means of reducing the level of the public good (the tax instrument would be completely ineffective if $\mu=1$ ). Note also that the right-hand side of equation (46) may be

\footnotetext{
${ }^{20}$ If $G^{G o v}=0$, the $S N M C$ component in equations (43) and (44) would be present also in equation (45).

${ }^{21}$ A similar incentive to tax charitable giving (as such giving leads to overprovision of a public good) was found by Blumkin and Sadka (2007) in the context of a signaling model.
} 
positive (and will always be larger than -1) even in the absence of any transaction cost. Turning finally to equation (45), the new term proportional to $\omega_{g^{1}}>0$ on the right-hand side adjusts the welfare cost of the positional-giving externality for the fact that the low-ability type does not give to charity. Therefore, this component contributes to reduce the marginal tax on charitable giving implemented for the high-ability type.

\section{Type I Paternalism: The Government Does Not Value Changes in Relative Consumption and Relative Giving}

In the previous sections, we followed convention in assuming that the government is welfarist, which means that it respects all aspects of consumer preferences (including the warm glow of giving and concerns for relative consumption and charitable giving). In contrast, here we consider an alternative policy objective where the government does not respect the consumer preferences for relative consumption and relative charitable giving, although respecting all other aspects of these preferences.

Since the paternalist government does not respect the consumer preferences for relative consumption and relative giving, it would like each consumer to behave as if these concerns were absent. Following the approach developed in Aronsson and Johansson-Stenman (2018), the marginal utility of consumption and giving from the perspective of the paternalist government are $v_{c}^{i}$ and $v_{g}^{i}$, respectively, instead of $u_{c}^{i}=v_{c}^{i}+v_{\Delta c}^{i}$ and $u_{c}^{i}=v_{g}^{i}+v_{\Delta g}^{i}$ (which are interpretable as the private marginal utilities of consumption and giving). We assume throughout this subsection that the government respects all other aspects of consumer preferences, - an assumption that will be relaxed below where we consider paternalism also in terms of warm glow.

While the Lagrangean takes the same form as before, the government will in this case disregard the utility gain attached to increased relative consumption and relative charitable giving, respectively. The social first-order conditions for work hours and public good provision by the government remain as in equations (17), (18), and (21), whereas the social first-order conditions for private consumption and private contributions to the public good change to read

$$
L_{c^{1}}=v_{c}^{1}-\lambda\left(\hat{v}_{c}^{2}+\hat{v}_{\Delta c}^{2}\right)-\gamma n^{1}+\frac{n^{1}}{N} L_{\bar{c}}=0
$$




$$
\begin{gathered}
L_{c^{2}}=\delta v_{c}^{2}+\lambda\left(\hat{v}_{c}^{2}+\hat{v}_{\Delta c}^{2}\right)-\gamma n^{2}+\frac{n^{2}}{N} L_{\bar{c}}=0, \\
L_{g^{1}}=v_{g}^{1}-\lambda\left(\hat{v}_{g}^{2}+\hat{v}_{\Delta g}^{2}\right)+v_{G}^{1}(1-\mu) n^{1}+(\delta+\lambda) v_{G}^{2}(1-\mu) n^{1}-\lambda \hat{v}_{G}^{2}(1-\mu) n^{1} \\
-\gamma n^{1}+\omega_{g^{1}}+\frac{n^{1}}{N} L_{\bar{g}}=0 \\
L_{g^{2}}=\delta v_{g}^{2}+\lambda\left(v_{g}^{2}+v_{\Delta g}^{2}\right)+v_{G}^{1}(1-\mu) n^{2}+(\delta+\lambda) v_{G}^{2}(1-\mu) n^{2}-\lambda \hat{v}_{G}^{2}(1-\mu) n^{2} \\
-\gamma n^{2}+\omega_{g^{2}}+\frac{n^{2}}{N} L_{\bar{g}}=0
\end{gathered}
$$

where

$$
\begin{aligned}
& L_{\bar{c}}=\lambda\left(u_{\bar{c}}^{2}-\hat{u}_{\bar{c}}^{2}\right)=-\lambda\left(v_{\Delta c}^{2}-\hat{v}_{\Delta c}^{2}\right), \\
& L_{\bar{g}}=\lambda\left(u_{\bar{g}}^{2}-\hat{u}_{\bar{g}}^{2}\right)=-\lambda\left(v_{\Delta g}^{2}-\hat{v}_{\Delta g}^{2}\right) .
\end{aligned}
$$

We have written the social first-order conditions in terms of the function $v^{i}(\cdot)$, which facilitates the distinction between the social and private marginal utilities. Yet, although the government does not derive utility directly from the consumers' preferences for relative consumption and relative giving, these preferences nevertheless affect the self-selection constraint and, therefore, equations (48)-(51). This explains why the private (instead of social) marginal utilities of consumption and giving, respectively, are proportional to $\lambda$ (the Lagrange multiplier of the self-selection constraint). Note also from equations (52) and (53) that the welfare effects of increased reference consumption and reference giving differ from those derived in the welfarist case, see equations (22) and (23), since variations in $\bar{c}$ and $\bar{g}$ only affect welfare via the self-selection constraint under the paternalist policy.

\subsection{Marginal Income Taxation and Public Good Provision}

Let $\operatorname{SMRS}_{z, c}^{i}=v_{z}^{i} / v_{c}^{i}$ denote the social marginal rate of substitution between leisure and private consumption and $S M R S_{G, c}^{i}=v_{G}^{i} / v_{c}^{i}$ the social marginal rate of substitution between the public good and private consumption, in both cases for ability-type $i$. Thus, $S M R S_{z, c}^{i}$ and $S M R S_{G, c}^{i}$ reflect how the individual would value leisure time and the public good, respectively, on the margin, if the relative consumption and relative giving were held constant. Hence, these measures reflect how the government wants individuals to value leisure time and the public good, which makes it logical to use the notion of social marginal rates of substitution. We use the short notations 


$$
\begin{aligned}
\tau_{P}^{1} & =\frac{\lambda \hat{u}_{c}^{2}}{\gamma n^{1} w^{1}}\left[S M R S_{z, c}^{1}-\phi S M \hat{R} S_{z, c}^{2}\right] \\
\tau_{P}^{2} & =0
\end{aligned}
$$

to summarize the policy rules for marginal taxation that would follow if the government were to treat the measures of reference consumption and reference giving as exogenous. Albeit based on the SMRS functions, these expressions are analogous to their counterparts $\tau^{1}$ and $\tau^{2}$ in Section 4. The policy rules for marginal income taxation and public good provision are presented in Proposition 4.

Proposition 4. If the government does not respect the consumer preferences for relative consumption and relative giving, the policy rules for marginal income taxation are given as

$$
\begin{aligned}
& T^{\prime}\left(w^{1} l^{1}\right)=\tau_{P}^{1}+\left(1-\tau_{P}^{1}\right) \alpha^{1}+\left(1-\alpha^{1}\right) \frac{\lambda_{P}^{1}}{w^{1}} \frac{n^{1} v_{\Delta c}^{2}+n^{2} \hat{v}_{\Delta c}^{2}}{n^{1} N}, \\
& T^{\prime}\left(w^{2} l^{2}\right)=\alpha^{2}-\left(1-\alpha^{2}\right) \frac{\lambda_{P}^{2}}{w^{2}} \frac{n^{1} v_{\Delta c}^{2}+n^{2} \hat{v}_{\Delta c}^{2}}{n^{2} N},
\end{aligned}
$$

where $\lambda_{P}^{i}=\lambda S M R S_{z, c}^{i} / \gamma>0$ for $i=1,2$, while the optimal provision of the public good satisfies the following policy rule if $G^{G o v}>0$ :

$$
\begin{aligned}
& \sum_{i} n^{i} S M R S_{G, c}^{i}+\frac{\lambda \hat{v}_{c}^{2}}{\gamma}\left[S M R S_{G, c}^{1}-S M \hat{R} S_{G, c}^{2}\right] \\
& +\left(S M R S_{G, c}^{1}-S M R S_{G, c}^{2}\right) \frac{\lambda}{\gamma}\left(\frac{\hat{v}_{\Delta c}^{2} n^{2}+v_{\Delta c}^{2} n^{1}}{N}\right)=1
\end{aligned}
$$

Proof: See the Appendix.

The marginal tax policy in equations (54) and (55) are equivalent to the policy rules derived by Aronsson and Johansson-Stenman (2018) in a model without charitable giving. The policy rules of equations (54) and (55) are reminiscent of those derived in the welfarist case with two important exceptions. First, the corrective motive for taxation is now reflected in the typespecific degrees of consumption positionality instead of the average degree. As indicated above, the paternalist government does not try to internalize the (positional) externalities that relative consumption and relative giving concerns give rise to. Instead, it would like the individuals to behave as if these concerns were absent, and tries to correct for a behavioral failure that manifests itself in the individual's own degree of consumption positionality. Second, the way in which relative consumption concerns affect the marginal tax policy via the 
self-selection constraint - given by the final term on the right-hand side of equations (54) and (55) - differs from the corresponding effects derived under a welfarist government. This component is positive in the marginal income tax formula for the low-ability type and negative in the formula for the high-ability type. The intuition is that an increase in $c^{1}$ tightens the self-selection constraint (by increasing the utility of a potential mimicker), while an increase in $c^{2}$ relaxes the self-selection constraint (by increasing the utility of the highability type). These mechanisms are thoroughly described in Aronsson and JohanssonStenman (2018) and will not be further discussed here.

The policy rule for the public good is novel and differs somewhat from that derived for a welfarist government in Section 4, where the effects of the relative consumption concerns were summarized in terms of one single multiplier attached to the sum of the consumers' marginal willingness to pay for the public good. By contrast, the first row of equation (56) is analogous to the policy rule for public good provision under nonlinear income taxation derived by Boadway and Keen (1993) in a conventional model without any relative concerns, i.e., a second-best analogue to the Samuelson condition, albeit based on the SMRS functions defined above.

Relative consumption concerns affect the policy rule for public good provision solely through the self-selection constraint as reflected in the second row of equation (56). The intuition is that a decrease in $c^{1}$ contributes to relax the self-selection constraint and a decrease in $c^{2}$ to tighten the self-selection constraint, ceteris paribus, as discussed above in the context of marginal income taxation. For this particular reason, a reallocation from private to public consumption is less expensive if the funds are raised through taxation of the low-ability type instead of through taxation of the high-ability type. Thus, there is an incentive to overprovide (underprovide) the public good compared with the conventional policy rule in the first row if the low-ability type is willing to pay more (less) than the high-ability type for an increase in the public good in the sense that $S M R S_{G, c}^{1}>(<) S M R S_{G, c}^{2}$. Since one would normally expect $S M R S_{G, c}^{1}<S M R S_{G, c}^{2}$, the final term on the right-hand side of equation (56) is likely to imply underprovision compared with the conventional policy rule.

Proposition 4 reflects the same separation result as Proposition 1 above. This means that the policy rules for marginal income taxation and public good provision take the same forms (and 
reflect the same policy incentives) as in the absence of voluntary, private contributions to the public good. Again, the reason is that the private contributions are targeted through a direct instrument, i.e., the marginal tax/subsidies directed explicitly towards charitable giving, to which we turn in the next subsection. Note finally that leisure separability, as described in Definition 1, does not simplify the policy rules as much as it did in the welfarist model examined in Section 4. Introducing leisure separability would remove the second term on the right-hand side of equation (56), since the utility function used in Definition 1 implies $S M R S_{G, c}^{1}=S M \hat{R} S_{G, c}^{2}$, while it would not change the policy rules for marginal income taxation given in equations (54) and (55).

\subsection{Marginal Taxation of Charitable Giving under Interior Solutions}

To simplify the presentation of the results, we will also here start with the case where $g^{1}, g^{2}$, and $G^{G o v}$ are all positive at the social optimum, such that $\omega_{g^{1}}=\omega_{g^{2}}=\omega_{G^{G o v}}=0$. Let $S M R S_{g, c}^{i}=v_{g}^{i} / v_{c}^{i}$ denote the social marginal rate of substitution between charitable giving and private consumption for ability-type $i$, while $S M \hat{R} S_{g, c}^{2}=\hat{v}_{g}^{2} / \hat{v}_{c}^{2}$ denotes the corresponding social marginal rate of substitution for the mimicker. We can interpret $S M R S_{g, c}^{i}$ as reflecting how an individual of ability-type $i$ would value charitable contributions at the margin if her relative consumption and relative giving were held constant. As such, it also reflects how the government wants the individual to value private contributions to the public good. The optimal marginal taxes/subsidies to charitable contributions are characterized in Proposition 5.

Proposition 5. If (i) the government does not respect the consumer preferences for relative consumption and relative giving, (ii) $G^{G o v}>0$ at the social optimum, and (iii) both ability types contribute to charity, then the optimal marginal tax/subsidy rates on charitable giving take the form

$$
\begin{aligned}
T_{g}^{1} & =\frac{1-\alpha^{1}}{\varphi^{1}}\left(\frac{\lambda \hat{v}_{c}^{2}}{\gamma n^{1}}\left(S M \hat{R} S_{g, c}^{2}-S M R S_{g, c}^{1}\right)+\mu+\frac{\lambda \hat{v}_{\Delta g}^{2} n^{2}+\lambda v_{\Delta g}^{2} n^{1}}{\gamma n^{1} N}\right), \\
& +\beta^{1} M R S_{g, c}^{1}-1 \\
T_{g}^{2} & =\frac{1-\alpha^{2}}{\varphi^{2}}\left(\mu-\frac{\lambda \hat{v}_{\Delta g}^{2} n^{2}+\lambda v_{\Delta g}^{2} n^{1}}{\gamma n^{2} N}\right)+\beta^{2} M R S_{g, c}^{2}-1,
\end{aligned}
$$

where 


$$
\varphi^{1}=1+\frac{\lambda}{\gamma n^{1}} \frac{\hat{v}_{\Delta c}^{2} n^{2}+v_{\Delta c}^{2} n^{1}}{N}>1 \quad \text { and } \quad \varphi^{2}=1-\frac{\lambda}{\gamma n^{2}} \frac{\hat{v}_{\Delta c}^{2} n^{2}+v_{\Delta c}^{2} n^{1}}{N}<1
$$

Proof: See the Appendix.

Before we interpret Proposition 5 in greater detail, it is useful to consider the special case where (1) the transaction cost of charitable contributions is zero $(\mu=0)$ and (2) the selfselection constraint does not bind ( $\lambda=0)$, in which equations (57) and (58) reduce to read

$$
T_{g}^{i}=\beta^{i} M_{R} S_{g, c}^{i}-1=\beta^{i} \frac{1-\alpha^{i}}{1-\beta^{i}} \operatorname{SMRS}_{g, c}^{i}-1 \text { for } i=1,2 .
$$

The first term on the right-hand side of equation (59) is a corrective tax component. It reflects a pure paternalist motive for taxing charitable giving at the margin (such that the marginal subsidy falls short of 100 percent). Recall that $M R S_{g, c}^{i}$ is interpretable in terms of the individual's marginal willingness to pay for charitable giving, and the fraction $\beta^{i}$ of this marginal willingness to pay is attributable to concerns about relative charitable giving. This policy incentive arises because the government would like the individuals to behave as if they did not care about relative consumption and relative giving. Therefore, and in a way similar to the policy rules for marginal income taxation in equations (57) and (58), this policy component depends on the type-specific degrees of positionality instead of on the average degrees (based on which the corrective tax component was formed under welfarism). By examining the SMRS formulation of the policy rule, we can see that the marginal subsidy on charitable giving decreases (or the marginal tax increases) with the degree of charitable giving positionality, $\beta^{i}$, and that the marginal subsidy increases (or the marginal tax decreases) with the degree of consumption positionality, $\alpha^{i}$. The intuition is that a higher $\beta^{i}$ leads the individual to provide more of the public good, and a higher $\alpha^{i}$ leads the individual to provide less than she would have in the absence of any relative concerns, ceteris paribus. Note that this policy incentive would vanish if the individuals were completely non-positional in terms of charitable giving, in which case $\beta^{i}=0$. It is also worth pointing out that the corrective motive for taxation facing the paternalist government is present despite that equation (59) is based on the assumption that $\mu=0$, which distinguishes this policy rule from its counterpart under welfarism (equation [32]). 
Returning to the general case in Proposition 5, we can see that the first term on the right-hand side of equation (57) is analogous to its counterpart in equation (30), although it is based on the SMRS function (instead of the MRS functions). As such, this provides an incentive to marginally tax (subsidize) charitable giving by low-ability individuals, if a potential mimicker care more (less) than the low-ability type about warm glow. We can also see that $\mu>0$ (a positive marginal resource cost of charitable giving) induces the government to discourage charitable contributions via a lower marginal subsidy or higher marginal tax. The reason is the same as in the welfarist case addressed above: private contributions are costly whereas public provision is not, which makes private contributions less desirable from a social point of view, ceteris paribus.

By analogy to the policy rules for marginal income taxation described above, the final component in brackets in equation (57) and (58), respectively, depends on (i) the direct effects of $g^{1}$ and $g^{2}$ on the self-selection constraint and (ii) the partial welfare effect of an increase in the measure of reference giving, $L_{\bar{g}}=\partial L / \partial \bar{g}$. Note that this component is positive in the formula implemented for the low-ability type and negative in the formula implemented for the high-ability type. Noting that $\bar{g}$ depends positively on both $g^{1}$ and $g^{2}$, an increase in $g^{1}$ contributes to tighten the self-selection constraint (by increasing the utility of the mimicker), while an increase in $g^{2}$ contributes to relax the self-selection constraint (by increasing the utility of the high-ability type), ceteris paribus. To relax the self-selection constraint, there is thus an incentive for the government to decrease $g^{1}$ and increase $g^{2}$, which can be accomplished through a higher marginal tax on the contributions to the public good by the low-ability type and a lower marginal tax on the contributions by the high-ability type.

However, as we explained in the context of marginal income taxation above, another way to relax the self-selection constraint is through a simultaneous decrease in $c^{1}$ and increase in $c^{2}$. This explains the variables $\varphi^{1}>1$ and $\varphi^{2}<1$ in the denominators of equations (57) and (58), respectively, which contribute to decrease the marginal tax on charitable contributions by the low-ability type and increase the marginal tax on contributions by the high-ability type. Whether this mechanism is dominated by, or dominates, the one described in the preceding paragraph is an empirical question. 
Two additional insights are worth pointing out. First, the corrective component in equations (57) and (58), i.e., $\beta^{i} M R S_{g, c}^{i}=\beta^{i}\left(1-\alpha^{i}\right) /\left(1-\beta^{i}\right) S M R S_{g, c}^{i}$, can alternatively be written as a scale factor. To see this, use $\beta^{i} M R S_{g, c}^{i}=\beta^{i}\left(1+T_{g}^{i}\right)$ based on the private first-order condition for charitable giving and substitute into equations (57) and (58). Rearrangements give

$$
\begin{aligned}
T_{g}^{1} & =\frac{1-\alpha^{1}}{1-\beta^{1}} \frac{1}{\varphi^{1}}\left(\frac{\lambda \hat{v}_{c}^{2}}{\gamma n^{1}}\left(S M \hat{R} S_{g, c}^{2}-S M R S_{g, c}^{1}\right)+\mu+\frac{\lambda}{\gamma n^{1}} \frac{\hat{v}_{\Delta g}^{2} n^{2}+v_{\Delta g}^{2} n^{1}}{N}\right)-1, \\
T_{g}^{2} & =\frac{1-\alpha^{2}}{1-\beta^{2}} \frac{1}{\varphi^{2}}\left(\mu-\frac{\lambda}{\gamma n^{2}} \frac{\hat{v}_{\Delta g}^{2} n^{2}+v_{\Delta g}^{2} n^{1}}{N}\right)-1 .
\end{aligned}
$$

In equations (60) and (61), the multiplier $\left(1-\alpha^{i}\right) /\left(1-\beta^{i}\right)$ attached to the components in brackets represents the paternalist government's incentive to correct for the two (perceived) behavioral failures. The intuition is the same as before: an increase in the type-specific degree of charitable giving positionality contributes to increase the marginal tax (or decrease the marginal subsidy), while an increase in the type-specific degree of consumption positionality works the other way around, ceteris paribus.

Second, leisure separability based on Definition 1 would only change Proposition 5 by eliminating the first term on the right-hand side of equation (57), since $\operatorname{SMR} S_{g, c}^{2}=S M R S_{g, c}^{1}$ under leisure separability. All other components of equation (57) would remain the same, and the marginal tax attached to charitable giving by the high-ability type would still take the form of equation (58). These implications of leisure separability are analogous to those described in the context of Proposition 4 above and suggest that leisure separability is a less useful simplifying assumption (and thus a less natural benchmark case) under paternalism than under welfarism.

\subsection{Marginal Taxation of Charitable Giving under Corner Solutions}

When it is socially undesirable that one of the ability types (or both) contributes to charity, the optimal tax treatment of charitable giving is based on exactly the same reasoning as under a welfarist government (as described in subsection 4.4). This means, here too, that the optimal policy rule for marginal taxation of charitable giving (in this case given in Proposition 5) would be replaced by an inequality constraint, showing the lowest marginal tax (or highest marginal subsidy) at which the individual does not contribute to charity. Therefore, the policy problem is to implement a marginal tax higher than or equal to this rate to ensure that the individual does not contribute at all. 
The other interesting corner solution is the case where $G^{G o v}=0$, which arises if voluntary contributions lead to overprovision of the public good compared with the policy rule ideally preferred by the government (in this case equation [54]). ${ }^{22}$ It is straightforward to show that this overprovision problem leads to an additional incentive to tax charitable giving at the margin, which is reminiscent of the mechanisms described under a welfarist government in equations (43) and (44). To see this, suppose that $g^{1}>0, g^{2}>0$, and $G^{G o v}=0$ at the social optimum. By analogy to the analysis carried out in subsection 4.4, let us define the net social marginal cost of public good provision (in this case from the perspective of the paternalist government) when $G^{G o v}=0$ as follows:

$$
\begin{aligned}
\operatorname{SNMC}^{p}\left(G^{G o v} \mid G^{G o v}=0\right) & =1-\left(\sum_{i} n^{i} \operatorname{SMRS}_{G, c}^{i}+\frac{\lambda \hat{v}_{c}^{2}}{\gamma}\left[S M R S_{G, c}^{1}-S M \hat{R} S_{G, c}^{2}\right]\right. \\
& +\left(\operatorname{SMR} S_{G, c}^{1}-S M R S_{G, c}^{2}\right) \frac{\left.\lambda\left(\frac{\hat{v}_{\Delta c}^{2} n^{2}+v_{\Delta c}^{2} n^{1}}{\gamma}\right)\right|_{G^{G o v}=0}>0}{N} .
\end{aligned}
$$

The optimal marginal tax treatment of charitable giving is summarized in Proposition 6.

Proposition 6. If $G^{G o v}=0, g^{1}>0$, and $g^{2}>0$ at the social optimum, equations (57) and (58) change to read

$$
\begin{aligned}
T_{g}^{1} & =\frac{1-\alpha^{1}}{\varphi^{1}}\left(\frac{\lambda \hat{v}_{c}^{2}}{\gamma n^{1}}\left(S M \hat{R} S_{g, c}^{2}-\operatorname{SMRS}_{g, c}^{1}\right)+\mu+\operatorname{SNMC}^{p}\left(G^{G o v} \mid G^{G o v}=0\right)(1-\mu)\right. \\
& \left.+\frac{\lambda \hat{v}_{\Delta g}^{2} n^{2}+\lambda v_{\Delta g}^{2} n^{1}}{\gamma n^{1} N}\right)+\beta^{1} M R S_{g, c}^{1}-1 \\
T_{g}^{2} & =\frac{1-\alpha^{2}}{\varphi^{2}}\left(\mu+S N M C^{p}\left(G^{G o v} \mid G^{G o v}=0\right)(1-\mu)-\frac{\lambda \hat{v}_{\Delta g}^{2} n^{2}+\lambda v_{\Delta g}^{2} n^{1}}{\gamma n^{2} N}\right) . \\
& +\beta^{2} \operatorname{MRS}_{g, c}^{2}-1
\end{aligned}
$$

The proof of Proposition 6 is analogous to the proof of Proposition 5. Compared with equations (57) and (58), we can see that equations (62) and (63) contain an additional term on the right-hand side, i.e., $\operatorname{SNMC}^{p}\left(G^{G o v} \mid G^{G o v}=0\right)>0$. This additional policy incentive thus works to increase the marginal taxes on charitable giving. The intuition is the same as for the

\footnotetext{
${ }^{22}$ Contrary to the welfarist policy addressed in Section 4, a paternalist government uses the same policy rule for marginal taxation of charitable giving by each ability type, irrespective of whether the other ability type should contribute to charity at the social optimum. The reason is that the paternalist government aims at correcting for a type-specific behavioral failure; it does not attempt to correct for positional externalities.
} 
corresponding policies pursued by a welfarist government, which we addressed in Proposition 3 above: a higher marginal tax leads to less charitable giving and consequently reduces the public good to a level closer to that ideally preferred by the government.

\section{Type II Paternalism: The Government Respects Neither Relative Concerns Nor the Warm Glow of Giving}

In this section, we assume that the government respects neither the consumer preferences for relative consumption and relative giving (as in Section 5) nor the consumer preference for warm glow. As mentioned in the introduction, the latter follows the arguments laid out by Diamond (2006), who questions whether the warm glow of giving should be part of the social objective. $^{23}$

It is straightforward to show (see the Appendix) that the low-ability type should not contribute to the public good at all in a social optimum. The reason is that such contributions would tighten the self-selection constraint (without generating any direct social benefit due to the absence of social preferences for warm glow). On the other hand, increased charitable giving by the high-ability type contributes to relax the self-selection constraint and may thus benefit society even if the government does not share the consumer preference for warm glow. Although a corner solution for $G^{G o v}$ seems less likely here than under welfarism and Type I paternalism, such a solution can, nevertheless, not be ruled out a priori. Similarly, we cannot rule out the possibility that $g^{2}=0$ (such that $G=G^{G o v}>0$ ). To derive a (possible) policy rule for the marginal tax on charitable giving for the high-ability type, we will assume that $g^{2}>0$ and $G^{G o v}>0$ at the social optimum. ${ }^{24}$

The social first-order conditions for private consumption will remain as in equations (48) and (49), while those for voluntary contributions to charity by the high-ability type will change to read (for an interior solution)

\footnotetext{
${ }^{23}$ Such a paternalist approach could also be motivated based on the results of DellaVigna et al. (2012), who in a field-experimental design of door-to-door fundraising conclude that social pressure is a common reason for donating, and that it may even be the case that such charity campaigns on average reduce the net utility of potential givers. Somewhat similarly, Andreoni et al. (2017, p. 625) found based on a field experiment that "people avoid empathic stimulation to regulate their giving and guilt."

${ }^{24}$ Relaxing the assumption that $G^{G o v}>0$ implies an additional incentive to reduce the charitable giving through higher marginal taxation, which is analogous to the mechanisms underlying Propositions 3 (based on welfarism) and 6 (based on Type I paternalism).
} 


$$
\begin{aligned}
L_{g^{2}} & =\lambda\left(v_{g}^{2}+v_{\Delta g}^{2}\right)+v_{G}^{1}(1-\mu) n^{2}+(\delta+\lambda) v_{G}^{2}(1-\mu) n^{2}-\lambda \hat{v}_{G}^{2}(1-\mu) n^{2} \\
& -\gamma n^{2}+\frac{n^{2}}{N} L_{\bar{g}}=0
\end{aligned}
$$

The policy rules for marginal income taxation and the public good will remain as in Proposition 3. Equations (21), (49), and (64) together imply the following policy rule for the marginal tax/subsidy on charitable contributions by the high-ability type:

Proposition 7. Suppose that (i) the government respects neither the consumer preferences for relative consumption and relative giving nor the consumer preference for warm glow, (ii) $G^{G o v}>0$ at the social optimum, and (iii) the high-ability type gives to charity. Then, positive charitable giving by the low-ability type is never part of an optimal solution, while the optimal marginal tax/subsidy implemented on the charitable giving of the high-ability type takes the form

$$
\begin{aligned}
T_{g}^{2} & =\frac{1-\alpha^{2}}{\psi^{2}} \frac{\delta v_{g}^{2}}{\gamma n^{2}}+\beta^{2} M R S_{g, c}^{2}-1 \\
& =\frac{1-\alpha^{2}}{\psi^{2}} \frac{\delta}{\lambda}\left(\mu-\frac{\lambda v_{\Delta g}^{2}}{\gamma N}\left\{\frac{N}{n^{2}}-1\right\}-\frac{\lambda \hat{v}_{\Delta g}^{2}}{\gamma N}\right)+\beta^{2} M R S_{g, c}^{2}-1
\end{aligned}
$$

where

$$
\psi^{2}=1-\frac{\lambda}{\gamma n^{2}}\left(v_{c}^{2}+\frac{\hat{v}_{\Delta c}^{2} n^{2}+v_{\Delta c}^{2} n^{1}}{N}\right)<1 .
$$

Proof: See the Appendix.

Based on the assumptions of Proposition 7, there are two distinct motives for taxing charitable contributions at the margin. The second term on the right-hand side of equation (65) reflects the paternalist motive for reducing charitable contributions, i.e. from the fact that the government does not respect the consumer preferences for relative giving. As such, this component is analogous to (and has the same interpretation as) its counterpart in equation (58).

The first term on the right-hand side of equation (65) is novel and reflects the added paternalist motive of taxing the consumers' marginal benefit of warm glow. As explained above, the variable $v_{g}^{2}=u_{g}^{2}\left(1-\beta^{2}\right)$ is interpretable in terms of the high-ability type's marginal utility of warm glow. Based on the social first-order condition for charitable giving, one can show (as we do in the second row) that the higher the transaction cost of charitable giving, $\mu$, or the lower the marginal utility of relative charitable giving facing the high-ability type and 
the mimicker, respectively, (i.e., $v_{\Delta g}^{2}$ and $\hat{v}_{\Delta g}^{2}$ ), the higher the marginal utility of warm glow at the second-best optimum should be, ceteris paribus. The latter suggests that the desire to tax away warm glow should be balanced against the benefit of relaxing the self-selection constraint through a higher $g^{2}$.

Finally, the multiplier $\psi^{2}$ reflects the relative consumption concerns (which influence welfare, and consequently tax policy, via the self-selection constraint). Note that $\psi^{2}<1$ works in the direction of less generous tax treatment by scaling up the marginal tax component attached to warm glow. Again, the reason is that an increase in $c^{2}$ (through less charitable giving) contributes to relax the self-selection constraint.

\section{Numerical Simulations}

In this section, we supplement the theoretical analyses in Sections 4, 5, and 6 with numerical simulations. In doing so, we are able to go beyond the policy rules for marginal taxation addressed above and analyze the levels of marginal and average taxation as well as the overall allocations of consumption and leisure. Note that the main purpose here is to illustrate how the optimal tax and redistribution policies vary with key parameters of the model and across policy objectives, and not to try to mimic real world economies. ${ }^{25}$

\subsection{The Numerical Model and Benchmark Simulation Results}

The theoretical results presented in Sections 4, 5, and 6 were derived based on the general governmental objective of achieving a Pareto-efficient resource allocation. The policy rules for marginal taxation and public provision presented above are thus necessary conditions for maximizing any social welfare function that fulfills the Pareto criterion, as long as it is consistent with the assumed redistribution profile. ${ }^{26}$ However, the levels of marginal (and average) taxation, the level of public good provision, as well as the overall redistribution policy will clearly depend on which specific social welfare function we use and on the functional assumptions underlying the individual utility functions.

\footnotetext{
${ }^{25}$ All simulations are based on the two-type models examined in the theoretical sections.

${ }^{26} \mathrm{We}$ assumed that the government wants to redistribute from the high-ability type to the low-ability type (referred to as the "normal case" by Stiglitz, 1982). This assumption is not needed in the numerical analysis set out below, where the form of the social welfare function will imply redistribution from the high-ability to the low-ability type.
} 
We assume that all individuals share a common utility function, namely

$$
\begin{aligned}
U^{i} & =\ln \left((1-\alpha) c^{i}+\alpha\left(c^{i}-\bar{c}\right)\right)+\eta \ln \left(z^{i}\right)+\rho \ln (G)+\sigma \ln \left(1+(1-\beta) g^{i}+\beta\left(g^{i}-\bar{g}\right)\right), \\
& =\ln \left(c^{i}-\alpha \bar{c}\right)+\eta \ln \left(z^{i}\right)+\rho \ln (G)+\sigma \ln \left(1+g^{i}-\beta \bar{g}\right)
\end{aligned},
$$

where $G=G^{G o v}+(1-\mu) \sum_{i} n^{i} g^{i}$ according to equation (4). In equation (66), $\eta, \rho, \sigma, \alpha$, and $\beta$ are fixed parameters, and superscript $i$ refers to ability type (as before). It is immediate from the formulation on the first line that all individuals (including a potential mimicker) will be characterized by the same degree of consumption positionality, equal to $\alpha$, and the same degree of charitable giving positionality, equal to $\beta$.

The private first-order conditions for work hours and charitable giving (assuming an interior solution) become

$$
\begin{aligned}
M R S_{z c}^{i} & =\eta \frac{c^{i}-\alpha \bar{c}}{z^{i}}=w^{i}\left(1-T_{w l}^{i}\right), \\
M R S_{g c}^{i} & =\sigma \frac{c^{i}-\alpha \bar{c}}{1+g^{i}-\beta \bar{g}}=1+T_{g}^{i} .
\end{aligned}
$$

Turning to the optimal tax problem, we follow much earlier literature in assuming a utilitarian social welfare function

$$
W=n^{1} U^{1}+n^{2} U^{2}
$$

The self-selection constraint takes the following form:

$$
\begin{aligned}
& \ln \left(c^{2}-\alpha \bar{c}\right)+\eta \ln \left(z^{2}\right)+\sigma \ln \left(1+g^{2}-\beta \bar{g}\right) \\
& \geq \ln \left(c^{1}-\alpha \bar{c}\right)+\eta \ln \left(1-\phi l^{1}\right)+\sigma \ln \left(1+g^{1}-\beta \bar{g}\right)
\end{aligned} .
$$

The social decision problem is to choose $l^{1}, c^{1}, l^{2}, c^{2}, g^{1}, g^{2}$, and $G^{G o v}$ to maximize the social welfare function given in equation (67) subject to the self-selection and resource constraints. Note that the self-selection constraint is here independent of the level of the public good, $G$.

As in the theoretical sections, we distinguish between a conventional welfarist government and the two paternalist governments (referred to as Type I and Type II paternalism). We use a common set of baseline parameters as our starting point as follows: $n^{1}=0.8$ and $n^{2}=0.2$, i.e., there are four times as many low-ability as high-ability individuals; $w^{1}=50$ and $w^{2}=200$, i.e., the before-tax wage rate is four times higher for high-ability individuals than for low-ability individuals; and $\eta=0.7$ and $\rho=0.4$, reflecting the relative weights of the 
leisure and public good terms, respectively, in the utility function compared with the private consumption term.

We are going to present results for different values of the degree of consumption positionality, $\alpha$, the degree of charitable giving positionality, $\beta$, the strength of the preference for charitable giving, $\sigma$, and the transaction cost, $\mu$. Each such parameter will be varied separately with the other parameters held constant at their baseline values, given by $\sigma=0.03, \alpha=0.2, \beta=0.25$, and $\mu=0.4$. These baseline parameters were chosen with the aim of illustrating the theoretical results and mechanisms, rather than necessarily providing a good approximation of likely parameters in a real economy.

Before presenting the main results (by varying the key parameters mentioned above), we will consider a reference scenario where the individuals do not derive any utility from charitable giving and the preferences are completely non-positional. This reference scenario corresponds to the special case of our model where $\alpha=\beta=\sigma=0$, which, in turn, coincides with a conventional model of optimal taxation. This provides a natural starting point and simplifies the presentation of the main results. Table 1 presents the optimal tax and redistribution policies implicit in this reference scenario.

Note first the non-surprising result that without any weight attached to charitable giving in the utility function $(\sigma=0)$, there will be no charitable giving at all in the social optimum. Correspondingly, the optimal marginal tax on charitable giving should be larger than -1 , which simply means that it is optimal that the government subsidizes charitable giving by less than $100 \%$. In doing so, the government ensures that neither ability type contributes voluntarily to the public good, which is socially optimal based on the assumptions in the reference scenario. Consequently, we also find that $G=G^{G o v}$, i.e., only the government contributes to the public good. Equally non-surprising, in the absence of any relative concerns and preferences for charitable giving, all results are the same for each of the three versions of the model. 
Table 1. Reference scenario without any relative concerns and preferences for charitable giving $(\alpha=\beta=\sigma=0)$

\begin{tabular}{|c|c|c|c|c|c|c|c|c|c|c|c|c|c|}
\hline \multicolumn{2}{|c|}{ Private Consumption } & \multicolumn{2}{|c|}{ Leisure } & \multicolumn{2}{|c|}{ Charitable giving } & \multirow{2}{*}{$\begin{array}{l}\text { Governm. } \\
\text { public } \\
\text { goods } \\
G^{\text {Gov }}\end{array}$} & \multirow{2}{*}{$\begin{array}{l}\begin{array}{l}\text { Total } \\
\text { public } \\
\text { goods }\end{array} \\
G\end{array}$} & \multicolumn{2}{|c|}{ Marginal labor tax rates } & \multicolumn{2}{|c|}{$\begin{array}{l}\text { Marginal charitable } \\
\text { giving tax rates }\end{array}$} & \multicolumn{2}{|c|}{ Average tax rates } \\
\hline$c^{1}$ & $c^{2}$ & $l^{1}$ & $l^{2}$ & $g^{1}$ & $g^{2}$ & & & $T^{\prime}\left(w^{1} l^{1}\right)$ & $T^{\prime}\left(w^{2} l^{2}\right)$ & $T_{g}^{1}$ & $T_{g}^{2}$ & $T_{A}^{1}$ & $T_{A}^{2}$ \\
\hline 28.04 & 68.95 & 0.51 & 0.76 & 0 & 0 & 14.49 & $\begin{array}{r}\text { farism } \\
14.49\end{array}$ & 0.2 & 0 & $>-1$ & $>-1$ & -0.1 & 0.55 \\
\hline 28.04 & 68.95 & 0.51 & 0.76 & 0 & 0 & $14.49^{\text {Type }}$ & $\begin{array}{l}\text { aternali } \\
14.49\end{array}$ & 0.2 & 0 & $>-1$ & $>-1$ & -0.1 & 0.55 \\
\hline 28.04 & 68.95 & 0.51 & 0.76 & 0 & 0 & $\begin{array}{l}\text { Type } \\
14.49^{\text {T. }}\end{array}$ & $\begin{array}{l}\text { aternali } \\
14.49\end{array}$ & 0.2 & 0 & $>-1$ & $>-1$ & -0.1 & 0.55 \\
\hline
\end{tabular}

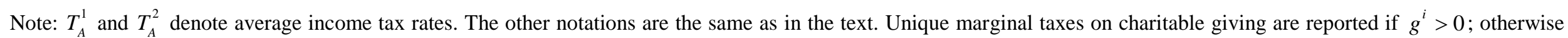
inequality conditions are reported. For example, $>-0.3$ means that the marginal tax rate should be higher than -0.3 (i.e., that the subsidy should be lower than 0.3 ). 
The reference scenario in Table 1 implies substantial redistribution from the high-ability to the low-ability type via the tax system. This can be seen from the negative average income tax rate facing the low-ability type, $T_{A}^{1}$, and the positive, and quite high, average income tax rate facing the high-ability type, $T_{A}^{2}$. This is of course a direct result of the concavity of the logarithmic utility function. However, there is still a substantial inequality in the sense that the consumption per high-ability individual is more than twice the consumption per low-ability individual. By comparison, with the functional form assumption for the utility function and the assumed social welfare function, a first-best resource allocation (if it were implementable) would lead to perfect equalization of the private consumption among individuals. Therefore, the self-selection constraint implies, quite realistically, a severe restraint on the redistribution policy. With respect to marginal income taxation, we observe, consistent with the theoretical result in Proposition 1 and Stiglitz (1982), for the case without any relative consumption concerns (such that $\alpha=0$ ), that the marginal income tax is positive for the low-ability type and zero for the high-ability type.

Let us now leave the conventional model of optimal taxation, as illustrated by the reference scenario, and examine how variation in the preference for charitable giving, $\sigma$, the degree of consumption positionality, $\alpha$, the degree of charitable giving positionality, $\beta$, and the transaction cost, $\mu$, affect the marginal tax and redistribution policy. As mentioned above, each of these parameters will be varied separately, whereas the other parameters will be held constant at their baseline values.

\subsection{Variation in Preferences for Charitable Giving}

Table 2 shows how the marginal tax policy and overall resource allocation depend on the strength of the preferences for charitable giving, $\sigma$, when $\alpha=0.2, \beta=0.25$, and $\mu=0.4$. Consider first the case where people have no preferences for charitable giving, such that $\sigma=0$. Then, again, we observe zero charitable giving. But we can also see that the marginal income tax rates are higher for both ability types than in the reference scenario reported in Table 1. The reason is that we have introduced relative consumption concerns here, i.e., $\alpha=0.2>0$, implying that the marginal income tax rates are modified correspondingly in line with Proposition 1; see Aronsson and Johansson-Stenman (2008, 2018) for more detailed discussions on these mechanisms. In addition, the tax system is much more redistributive here 
than in the reference scenario in that the average taxes are lower (more negative) for the lowability type and higher for the high-ability type.

Turning to the more interesting cases where $\sigma>0$, we can see from Table 2 that charitable giving should typically be subsidized at the margin in all three regimes, albeit at different rates. In the welfarist case, the marginal subsidy on charitable giving is the same for both ability types, which is a consequence of the functional form assumption for the utility function, i.e., equation (64), where the degrees of positionality are fixed and common for all, and leisure is weakly separable from the other goods in the utility function. Consequently, there are no positionality differences between a potential mimicker and the low-ability type (neither in terms of consumption nor in terms of charitable giving), and there is no difference between a potential mimicker and the low-ability type in terms of the marginal willingness to pay for charitable giving. Equations (30) and (31) in Proposition 2 then reduce to equation (32) such that $T_{g}^{1}=T_{g}^{2}$.

Under Type I paternalism, the high-ability type receives a slightly higher marginal subsidy than the low-ability type. As pointed out in the interpretation of Proposition 5, the reason is that the government can relax the self-selection constraint through a simultaneous increase in $g^{2}$ and decrease in $g^{1}$, which in turn motivates the differential tax treatment between ability types. However, despite the differences between the welfarist and paternalist governments (and in particular that the motive for corrective policy differs between them in a fundamental way), the numerical results imply that the marginal subsidies on charitable giving are very similar under Type I paternalism and welfarism. The marginal income tax rates implemented for the high-ability type, on the other hand, are lower under the paternalist regimes than under welfarism. The latter result is a direct consequence of our theoretical model in combination with a separable utility function. In terms of the overall redistribution, leisure, charitable giving, and private as well as public consumption, the optimal allocations are quite similar in the welfarist and Type I paternalist regimes.

The marginal tax treatment of charitable giving under Type II paternalism is very different from that under the other two regimes. Here, we shall always tax the low-ability type's charitable giving at a high enough marginal rate to ensure that these individuals decide not to contribute to charity at all. The high-ability type should still contribute in the cases considered here, although at much lower levels compared with under welfarism and Type I paternalism, 
and the marginal subsidy on charitable giving is correspondingly much lower here than under the other regimes. Therefore, the direct governmental contributions to the public good play a more important role under Type II paternalism than under the other two regimes.

As expected, the optimal level of charitable giving increases with $\sigma$. It is thus natural that the government contributes less to the public good when $\sigma$ increases, in particular in the welfarist and Type I paternalist regimes. Interestingly, this decrease in governmental provision of the public good more than offsets the increased contributions through charitable giving, which is due to the transaction cost. Moreover, for very high levels of $\sigma$, such as $\sigma=0.3$, and correspondingly large charitable contributions, we obtain a corner solution under the welfarist and Type I paternalist regimes such that $G^{G o v}=0$, consistent with the theoretical results in subsections 4.5 and 5.3. As can be seen from Table 2, we do not report any results for $\sigma=0.3$ under the Type II paternalist regime. The reason is that this government's objective function is not consistent with the assumed individual utility function for sufficiently large values of $\sigma$. Basically, in the social optimum condition for zero charitable giving by low-ability individuals, the utility term reflecting charitable giving, $\sigma \ln \left(1+g^{1}-\beta \bar{g}\right)=\sigma \ln (1-\beta \bar{g})=\sigma \ln \left(1-0.2 \beta g^{2}\right)=\sigma \ln \left(1-0.05 g^{2}\right)$, is not defined for $g^{2} \geq 20$. This finding may throw light on both the realism of the chosen utility function and on the realism of the governmental objective function. Due to space limitations, we will not dwell further on this issue here, however.

Overall, except for the major differences in the governmental contribution to the public good and the marginal tax treatment of charitable giving, the optimal marginal income tax and redistribution policy under Type II paternalism is similar to that under Type I paternalism. This result was expected, since the only difference between paternalism of types I and II relates to how the policy maker treats the warm glow of giving, which is important primarily from the perspectives of public good provision and the tax treatment of charitable giving.

Table 2 also shows that the marginal income tax rate for the low-ability type is similar across the three models and levels of $\sigma$, whereas the marginal income tax rate implemented for the high-ability type is much higher in the welfarist model than in the two paternalist models, again regardless of $\sigma$. 
Table 2. Simulation results: variation in the preferences for charitable giving, $\sigma$.

\begin{tabular}{|c|c|c|c|c|c|c|c|c|c|c|c|c|c|c|}
\hline \multirow{2}{*}{$\begin{array}{l}\text { Charitable } \\
\text { giving } \\
\text { parameter } \\
\sigma\end{array}$} & \multicolumn{2}{|c|}{$\begin{array}{l}\text { Private } \\
\text { Consumption }\end{array}$} & \multicolumn{2}{|c|}{ Leisure } & \multicolumn{2}{|c|}{ Charitable giving } & \multirow{2}{*}{$\begin{array}{l}\text { Governm. } \\
\text { public } \\
\text { goods }\end{array}$} & \multirow{2}{*}{$\begin{array}{l}\begin{array}{l}\text { Total } \\
\text { public } \\
\text { goods }\end{array} \\
G\end{array}$} & \multicolumn{2}{|c|}{ Marginal labor tax rates } & \multicolumn{2}{|l|}{$\begin{array}{l}\text { Marginal } \\
\text { charitable } \\
\text { tax rates }\end{array}$} & \multicolumn{2}{|c|}{ Average tax rates } \\
\hline & $c^{1}$ & $c^{2}$ & $l^{1}$ & $l^{2}$ & $g^{1}$ & $g^{2}$ & & & $T^{\prime}\left(w^{1} l^{1}\right)$ & $T^{\prime}\left(w^{2} l^{2}\right)$ & $T_{g}^{1}$ & $T_{g}^{2}$ & $T_{A}^{1}$ & $T_{A}^{2}$ \\
\hline \multicolumn{15}{|c|}{ Welfarism } \\
\hline 0.00 & 29.67 & 62.4 & 0.51 & 0.76 & 0 & 0 & 14.49 & 14.49 & 0.36 & 0.20 & -1 & -1 & -0.17 & 0.59 \\
\hline 0.02 & 29.72 & 61.91 & 0.51 & 0.76 & 0.17 & 1.68 & 14.18 & 14.46 & 0.36 & 0.20 & -0.57 & -0.57 & -0.17 & 0.58 \\
\hline 0.06 & 29.37 & 60.31 & 0.52 & 0.77 & 3.13 & 7.48 & 11.82 & 14.22 & 0.35 & 0.20 & -0.57 & -0.57 & -0.26 & 0.56 \\
\hline 0.10 & 29.02 & 58.79 & 0.52 & 0.77 & 6.01 & 12.99 & 9.54 & 13.99 & 0.35 & 0.20 & -0.57 & -0.57 & -0.34 & 0.54 \\
\hline 0.30 & 27.32 & 52.21 & 0.56 & 0.8 & 18.68 & 35.57 & 0 & 13.23 & 0.34 & 0.2 & -0.56 & -0.56 & -0.65 & 0.45 \\
\hline \multicolumn{15}{|c|}{ Type I Paternalism } \\
\hline 0.00 & 29.91 & 65.81 & 0.51 & 0.78 & 0 & 0 & 14.38 & 14.38 & 0.36 & 0.08 & $>-1$ & $>-1$ & -0.17 & 0.58 \\
\hline 0.02 & 29.96 & 65.16 & 0.51 & 0.78 & 0.18 & 1.96 & 14.04 & 14.36 & 0.35 & 0.09 & -0.57 & -0.59 & -0.18 & 0.57 \\
\hline 0.06 & 29.59 & 63.28 & 0.52 & 0.78 & 3.16 & 8.27 & 11.62 & 14.12 & 0.35 & 0.09 & -0.57 & -0.59 & -0.26 & 0.54 \\
\hline 0.10 & 29.23 & 61.51 & 0.53 & 0.79 & 6.06 & 14.21 & 9.28 & 13.89 & 0.35 & 0.09 & -0.57 & -0.59 & -0.34 & 0.52 \\
\hline 0.30 & 27.51 & 54 & 0.56 & 0.82 & 18.4 & 37.4 & 0 & 13.32 & 0.33 & 0.1 & -0.55 & -0.57 & -0.64 & 0.44 \\
\hline \multicolumn{15}{|c|}{ Type II Paternalism } \\
\hline 0.00 & 29.91 & 65.81 & 0.51 & 0.78 & 0 & 0 & 14.38 & 14.38 & 0.36 & 0.08 & $>-1$ & $>-1$ & -0.17 & 0.58 \\
\hline 0.02 & 29.95 & 65.6 & 0.51 & 0.78 & 0 & 0.44 & 14.33 & 14.38 & 0.36 & 0.09 & $>-0.54$ & -0.18 & -0.17 & 0.58 \\
\hline 0.06 & 30.51 & 62.92 & 0.51 & 0.79 & 0 & 3.90 & 13.95 & 14.42 & 0.34 & 0.09 & $>0.72$ & -0.29 & -0.2 & 0.57 \\
\hline 0.10 & 31.55 & 58.31 & 0.5 & 0.8 & 0 & 9.03 & 13.41 & 14.49 & 0.32 & 0.11 & $>3.41$ & -0.47 & -0.25 & 0.58 \\
\hline
\end{tabular}

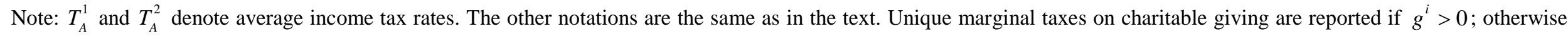
inequality conditions are reported. For example, $>-0.3$ means that the marginal tax rate should be higher than -0.3 (i.e., that the subsidy should be lower than 0.3 ). 
Given the functional form assumption for the utility function (which is such that all agents are equally positional), equation (23) implies that the marginal income tax rate implemented for the high-ability type equals the (common) degree of consumption positionality, whereas the marginal income tax rate implemented for the low-ability type will exceed the degree of consumption positionality, under welfarism. The simulation results confirm these patterns.

In the paternalist models, we saw in Section 5 that the second-best efficient marginal income tax rate implemented for the high-ability type falls short of this type's degree of consumption positionality, while the marginal income tax facing the low-ability type exceeds the typespecific degree of positionality. The intuition is that the paternalist government may relax the self-selection constraint through a policy-induced increase in the high-ability type's private consumption and decrease in the low-ability type's ditto. An interesting insight from the table is, therefore, that the desire to relax the self-selection constraint may lead a paternalist government to implement a much lower marginal income tax for the high-ability type than would be motivated by this type's behavioral failure, i.e., a much lower marginal tax than would be chosen under first-best conditions.

\subsection{Variation in the Degree of Consumption Positionality}

In this subsection, we examine how the optimal tax and expenditure policies respond to variation in the degree of consumption positionality, $\alpha$, while the other parameters are held constant at the baseline values presented above. The results are presented in Table 3. Note that both ability types contribute to the public good in the social optimum under welfarism and Type I paternalism, allowing us to illustrate how the marginal tax treatment of charitable giving varies with the degree of consumption positionality.

We emphasize three basic observations from Table 3. First, increased consumption positionality makes the tax system more redistributive. We can see that the higher the degree of consumption positionality, the higher the consumption per low-ability individual and the lower the consumption per high-ability individual will be, ceteris paribus. The same information is revealed by examining the relationship between the degree of consumption positionality and the average tax rates. This is also in line with earlier research based on numerical models (e.g., Kanbur and Tuomala, 2013; Aronsson and Johansson-Stenman, 2018). 
Table 3. Simulation results: variation in the degree of consumption positionality, $\alpha$.

\begin{tabular}{|c|c|c|c|c|c|c|c|c|c|c|c|c|c|c|}
\hline \multirow{2}{*}{$\begin{array}{l}\text { Degree of } \\
\text { consumption } \\
\text { positionality } \\
\alpha\end{array}$} & \multicolumn{2}{|c|}{$\begin{array}{l}\text { Private } \\
\text { Consumption }\end{array}$} & \multicolumn{2}{|c|}{ Leisure } & \multicolumn{2}{|c|}{ Charitable giving } & \multirow{2}{*}{$\begin{array}{l}\text { Governm. } \\
\text { public } \\
\text { goods }\end{array}$} & \multirow{2}{*}{$\begin{array}{l}\begin{array}{l}\text { Total } \\
\text { public } \\
\text { goods }\end{array} \\
G\end{array}$} & \multicolumn{2}{|c|}{ Marginal labor tax rates } & \multicolumn{2}{|c|}{$\begin{array}{l}\text { Marginal } \\
\text { charitable giving } \\
\text { tax rates }\end{array}$} & \multicolumn{2}{|c|}{ Average tax rates } \\
\hline & $c^{1}$ & $c^{2}$ & $l^{1}$ & $l^{2}$ & $g^{1}$ & $g^{2}$ & & & $T^{\prime}\left(w^{1} l^{1}\right)$ & $T^{\prime}\left(w^{2} l^{2}\right)$ & $T_{g}^{1}$ & $T_{g}^{2}$ & $T_{A}^{1}$ & $T_{A}^{2}$ \\
\hline \multicolumn{15}{|c|}{ Welfarism } \\
\hline 0.00 & 28.04 & 67.87 & 0.51 & 0.76 & 0.92 & 3.16 & 13.58 & 14.40 & 0.20 & 0 & -0.47 & -0.47 & -0.13 & 0.53 \\
\hline 0.20 & 29.64 & 61.5 & 0.51 & 0.76 & 0.92 & 3.16 & 13.58 & 14.4 & 0.36 & 0.20 & -0.57 & -0.57 & -0.19 & 0.58 \\
\hline 0.40 & 31.23 & 55.13 & 0.51 & 0.76 & 0.92 & 3.16 & 13.58 & 14.4 & 0.52 & 0.40 & -0.68 & -0.68 & -0.26 & 0.62 \\
\hline 0.60 & 32.82 & 48.75 & 0.51 & 0.76 & 0.92 & 3.16 & 13.58 & 14.4 & 0.68 & 0.60 & -0.79 & -0.79 & -0.32 & 0.66 \\
\hline \multicolumn{15}{|c|}{ Type I Paternalism } \\
\hline 0.00 & 28.08 & 67.64 & 0.51 & 0.76 & 0.89 & 4.02 & 13.49 & 14.4 & 0.2 & 0 & -0.44 & -0.56 & -0.13 & 0.53 \\
\hline 0.20 & 29.87 & 64.68 & 0.51 & 0.78 & 0.93 & 3.58 & 13.42 & 14.3 & 0.35 & 0.09 & -0.57 & -0.59 & -0.2 & 0.56 \\
\hline 0.40 & 32.04 & 61.24 & 0.52 & 0.8 & 0.98 & 3.08 & 13.32 & 14.16 & 0.51 & 0.19 & -0.69 & -0.63 & -0.28 & 0.6 \\
\hline 0.60 & 34.78 & 57.1 & 0.52 & 0.82 & 1.02 & 2.53 & 13.14 & 13.93 & 0.67 & 0.34 & -0.8 & -0.69 & -0.38 & 0.64 \\
\hline \multicolumn{15}{|c|}{ Type II Paternalism } \\
\hline 0.00 & 28.26 & 68.01 & 0.51 & 0.76 & 0 & 1.69 & 14.28 & 14.48 & 0.19 & 0 & $>-0.07$ & -0.22 & -0.11 & 0.54 \\
\hline 0.20 & 30.05 & 65.09 & 0.51 & 0.78 & 0 & 1.24 & 14.24 & 14.39 & 0.35 & 0.09 & $>-0.28$ & -0.20 & -0.18 & 0.57 \\
\hline 0.40 & 32.22 & 61.71 & 0.51 & 0.8 & 0 & 0.76 & 14.15 & 14.24 & 0.51 & 0.19 & $>-0.47$ & -0.19 & -0.26 & 0.61 \\
\hline 0.60 & 34.99 & 57.66 & 0.52 & 0.82 & 0 & 0.23 & 13.98 & 14.01 & 0.67 & 0.34 & $>-0.66$ & -0.16 & -0.35 & 0.65 \\
\hline
\end{tabular}

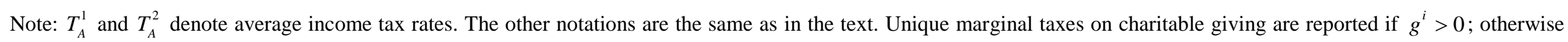
inequality conditions are reported. For example, > -0.3 means that the marginal tax rate should be higher than -0.3 (i.e., that the subsidy should be lower than 0.3 ). 
Second, the marginal income tax rates tend to increase with the degree of consumption positionality, which is perfectly in line with the underlying theory. The degree of consumption positionality (which is the same for everybody here) measures the marginal positional consumption externality per unit of consumption, which determines the corrective element of the marginal income taxes imposed by the welfarist government. It also reflects a behavioral failure that the paternalist governments want to correct for and, therefore, the corrective element of the marginal income taxes implemented by the paternalist governments. Thus, it makes perfect sense that the marginal income tax rates increase with respect to $\alpha$ also in the cases of Type I and Type II paternalism.

Third, the marginal tax treatment of charitable giving becomes more generous when the degree of consumption positionality increases, which is also in line with the theoretical analyses set out in Sections 4 and 5 for the welfarist and the Type I paternalist policy objectives. The intuition is that increased consumption positionality motivates a reallocation of resources from private consumption to charitable giving. This is so regardless of whether the government aims at internalizing the positional consumption externality or wants to correct for the behavioral failure that the relative consumption concerns give rise to. Under Type II paternalism, there is no such pattern. Instead, this government exploits that a higher $\alpha$ increases the marginal utility of consumption for the high-ability type. It may thus relax the self-selection constraint through increased private consumption (and hence decreased charitable giving) among high-ability individuals, which motivates lower marginal subsidies on charitable giving when $\alpha$ increases.

\subsection{Variation in the Degree of Charitable Giving Positionality}

Let us now examine the effects of variation in the (common-for-all) degree of charitable giving positionality. We can observe that an increase in this degree of positionality typically leads to less favorable marginal tax treatment of charitable giving - in this case lower marginal subsidies - under welfarism and Type I paternalism. The intuition is that an increase in $\beta$ implies a greater positional-giving externality (which the welfarist government wants to internalize) as well as a greater behavioral failure due to charitable giving positionality (which the Type I paternalist government of would like to avoid). An exception arises when the degree of charitable giving positionality increases from 0.4 to 0.6 , where instead the marginal subsidy on charitable giving by the high-ability type increases slightly under Type I paternalism. 
Table 4 Simulation results: variation in the degree of charitable giving positionality, $\beta$.

\begin{tabular}{|c|c|c|c|c|c|c|c|c|c|c|c|c|c|c|}
\hline \multirow{2}{*}{$\begin{array}{l}\begin{array}{l}\text { Degree of } \\
\text { charitable } \\
\text { giving } \\
\text { positionality }\end{array} \\
\beta\end{array}$} & \multicolumn{2}{|c|}{$\begin{array}{l}\text { Private } \\
\text { Consumption }\end{array}$} & \multicolumn{2}{|c|}{ Leisure } & \multicolumn{2}{|c|}{ Charitable giving } & \multirow{2}{*}{$\begin{array}{l}\text { Governm. } \\
\text { public } \\
\text { goods }\end{array}$} & \multirow{2}{*}{$\begin{array}{l}\text { Total } \\
\text { public } \\
\text { goods }\end{array}$} & \multicolumn{2}{|c|}{ Marginal labor tax rates } & \multicolumn{2}{|c|}{$\begin{array}{l}\text { Marginal } \\
\text { charitable giving } \\
\text { tax rates }\end{array}$} & \multicolumn{2}{|c|}{ Average tax rates } \\
\hline & $c^{1}$ & $c^{2}$ & $l^{1}$ & $l^{2}$ & $g^{1}$ & $g^{2}$ & & & $T^{\prime}\left(w^{1} l^{1}\right)$ & $T^{\prime}\left(w^{2} l^{2}\right)$ & $T_{g}^{1}$ & $T_{g}^{2}$ & $T_{A}^{1}$ & $T_{A}^{2}$ \\
\hline \multicolumn{15}{|c|}{ Welfarism } \\
\hline $\begin{array}{l}0.00 \\
0.20 \\
0.40 \\
0.60\end{array}$ & $\begin{array}{l}29.58 \\
29.62 \\
29.69 \\
29.83\end{array}$ & $\begin{array}{l}61.42 \\
61.48 \\
61.58 \\
61.78\end{array}$ & $\begin{array}{l}0.51 \\
0.51 \\
0.51 \\
0.51\end{array}$ & $\begin{array}{l}0.76 \\
0.76 \\
0.76 \\
0.76\end{array}$ & $\begin{array}{l}1.10 \\
0.97 \\
0.68 \\
0\end{array}$ & $\begin{array}{l}4.08 \\
3.36 \\
2.47 \\
1.2\end{array}$ & $\begin{array}{l}13.36 \\
13.53 \\
13.8 \\
14.34\end{array}$ & $\begin{array}{l}14.38 \\
14.40 \\
14.43 \\
14.49\end{array}$ & $\begin{array}{l}0.36 \\
0.36 \\
0.36 \\
0.36\end{array}$ & $\begin{array}{l}0.20 \\
0.20 \\
0.20 \\
0.20\end{array}$ & $\begin{array}{l}-0.68 \\
-0.60 \\
-0.47 \\
-0.21\end{array}$ & $\begin{array}{l}-0.68 \\
-0.60 \\
-0.47 \\
-0.2\end{array}$ & $\begin{array}{l}-0.20 \\
-0.20 \\
-0.19 \\
-0.17\end{array}$ & $\begin{array}{l}0.57 \\
0.57 \\
0.58 \\
0.59\end{array}$ \\
\hline \multicolumn{15}{|c|}{ Type I Paternalism } \\
\hline $\begin{array}{l}0.00 \\
0.20 \\
0.40 \\
0.60\end{array}$ & $\begin{array}{l}29.79 \\
29.85 \\
29.94 \\
30.07\end{array}$ & $\begin{array}{l}64.79 \\
64.71 \\
64.57 \\
64.25\end{array}$ & $\begin{array}{l}0.51 \\
0.51 \\
0.51 \\
0.51\end{array}$ & $\begin{array}{l}0.78 \\
0.78 \\
0.78 \\
0.78 \\
\end{array}$ & $\begin{array}{l}1.17 \\
0.99 \\
0.73 \\
0.43\end{array}$ & $\begin{array}{l}3.72 \\
3.6 \\
3.51 \\
3.76 \\
\end{array}$ & $\begin{array}{l}13.27 \\
13.39 \\
13.55 \\
13.69\end{array}$ & $\begin{array}{l}14.28 \\
14.3 \\
14.32 \\
14.35\end{array}$ & $\begin{array}{l}0.35 \\
0.35 \\
0.35 \\
0.35\end{array}$ & $\begin{array}{l}0.09 \\
0.09 \\
0.09 \\
0.09\end{array}$ & $\begin{array}{l}-0.69 \\
-0.6 \\
-0.44 \\
-0.12\end{array}$ & $\begin{array}{l}-0.63 \\
-0.6 \\
-0.57 \\
-0.58\end{array}$ & $\begin{array}{l}-0.21 \\
-0.20 \\
-0.20 \\
-0.19\end{array}$ & $\begin{array}{l}0.56 \\
0.56 \\
0.56 \\
0.56 \\
\end{array}$ \\
\hline \multicolumn{15}{|c|}{ Type II Paternalism } \\
\hline $\begin{array}{l}0.00 \\
0.20 \\
0.40 \\
0.60\end{array}$ & $\begin{array}{l}30.03 \\
30.04 \\
30.06 \\
30.1\end{array}$ & $\begin{array}{l}65.20 \\
65.12 \\
65.00 \\
64.80\end{array}$ & $\begin{array}{l}0.51 \\
0.51 \\
0.51 \\
0.51\end{array}$ & $\begin{array}{l}0.78 \\
0.78 \\
0.78 \\
0.78\end{array}$ & $\begin{array}{l}0 \\
0 \\
0 \\
0\end{array}$ & $\begin{array}{l}1.05 \\
1.19 \\
1.41 \\
1.79\end{array}$ & $\begin{array}{l}14.26 \\
14.25 \\
14.22 \\
14.18\end{array}$ & $\begin{array}{l}14.39 \\
14.39 \\
14.39 \\
14.39\end{array}$ & $\begin{array}{l}0.35 \\
0.35 \\
0.35 \\
0.35\end{array}$ & $\begin{array}{l}0.09 \\
0.09 \\
0.09 \\
0.09\end{array}$ & $\begin{array}{l}>-0.32 \\
>-0.29 \\
>-0.23 \\
>-0.13\end{array}$ & $\begin{array}{l}-0.15 \\
-0.19 \\
-0.25 \\
-0.33\end{array}$ & $\begin{array}{l}-0.18 \\
-0.18 \\
-0.18 \\
-0.18\end{array}$ & $\begin{array}{l}0.57 \\
0.57 \\
0.57 \\
0.57\end{array}$ \\
\hline
\end{tabular}

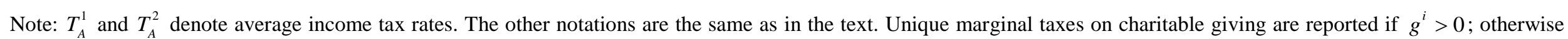
inequality conditions are reported. For example, $>-0.3$ means that the marginal tax rate should be higher than -0.3 (i.e., that the subsidy should be lower than 0.3 ). 
This difference between welfarism and Type I paternalism is not surprising, since the incentive faced by the paternalist government to relax the self-selection constraint by subsidizing charitable giving by the high-ability type becomes stronger when $\beta$ increases (and may eventually dominate the incentive to correct for the behavioral failure).

Under Type II paternalism, we find a positive relationship between the degree of charitable giving positionality and the marginal subsidy directed at contributions by the high-ability type. Recall that this government respects neither the relative concerns nor the consumer preference for warm glow, and $\beta$ is just the weight the consumer attaches to the relative component of charitable giving. From a corrective point of view, we would thus expect increases in $\beta$ to be less important for the marginal tax treatment of charitable giving under Type II paternalism than under the other two regimes, which is what Table 4 seems to suggest. A higher $\beta$ increases the marginal utility of charitable giving for the high-ability type, which the Type II paternalist government encourages (through a more favorable marginal tax treatment) in order to relax the self-selection constraint.

Table 4 also shows that variation in the degree of charitable giving positionality has little effect on the marginal and average income tax rates and on the overall redistribution in terms of consumption, leisure, and public good provision. This is, of course, partly a consequence of the functional form assumption for the utility function, where $\beta$ affects neither the marginal utility of private consumption nor the marginal utility of leisure. Thus, the policy incentives underlying income taxation remain largely unaffected by variations in the degree of charitable giving positionality.

\subsection{Variation in Transaction Cost}

Let us finally examine how variation in the transaction cost, $\mu$, influences the optimal resource allocation and the policy implications thereof. We can see from Table 5 that the larger the transaction cost, the lower the marginal subsidy on charitable giving, for each of the governmental policy objectives. As discussed in Section 4, for sufficiently large levels of $\mu$, the optimal marginal subsidy on charity may turn into a marginal tax. For the parameter values analyzed here, this never happens under the welfarist and Type I paternalist regimes, but it becomes the case under Type II paternalism for transaction costs of $\mu=0.5$ and larger. More generally, there is a substantial drop in the marginal subsidy rates when $\mu$ increases. 
Table 5 Simulation results: variation in the transaction cost, $\mu$.

\begin{tabular}{|c|c|c|c|c|c|c|c|c|c|c|c|c|c|c|}
\hline \multirow{2}{*}{$\begin{array}{l}\text { Transaction } \\
\text { cost } \\
\text { parameter } \\
\mu \mu\end{array}$} & \multicolumn{2}{|c|}{$\begin{array}{l}\text { Private } \\
\text { Consumption }\end{array}$} & \multicolumn{2}{|c|}{ Leisure } & \multicolumn{2}{|c|}{ Charitable giving } & \multirow{2}{*}{$\begin{array}{l}\text { Governm. } \\
\text { public } \\
\text { goods } \\
G^{\text {Gov }}\end{array}$} & \multirow{2}{*}{$\begin{array}{l}\text { Total } \\
\text { public } \\
\text { goods }\end{array}$} & \multicolumn{2}{|c|}{ Marginal labor tax rates } & \multicolumn{2}{|c|}{$\begin{array}{l}\text { Marginal } \\
\text { charitable giving } \\
\text { tax rates }\end{array}$} & \multicolumn{2}{|c|}{ Average tax rates } \\
\hline & $c^{1}$ & $c^{2}$ & $l^{1}$ & $l^{2}$ & $g^{1}$ & $g^{2}$ & & & $T^{\prime}\left(w^{1} l^{1}\right)$ & $T^{\prime}\left(w^{2} l^{2}\right)$ & $T_{g}^{1}$ & $T_{g}^{2}$ & $T_{A}^{1}$ & $T_{A}^{2}$ \\
\hline \multicolumn{15}{|c|}{ Welfarism } \\
\hline 0.00 & 29.45 & 61.22 & 0.51 & 0.76 & 12.54 & 26.39 & 0 & 15.31 & 0.36 & 0.20 & -0.93 & -0.93 & -0.63 & 0.43 \\
\hline 0.25 & 29.55 & 61.38 & 0.51 & 0.76 & 2.26 & 5.84 & 12.13 & 14.37 & 0.36 & 0.20 & -0.73 & -0.73 & -0.24 & 0.56 \\
\hline 0.50 & 29.69 & 61.58 & 0.51 & 0.76 & 0.47 & 2.27 & 14.01 & 14.43 & 0.36 & 0.20 & -0.47 & -0.47 & -0.18 & 0.58 \\
\hline 0.75 & 29.78 & 61.78 & 0.51 & 0.76 & 0 & 1.15 & 14.41 & 14.47 & 0.36 & 0.20 & -0.28 & -0.22 & -0.17 & 0.59 \\
\hline \multicolumn{15}{|c|}{ Type I Paternalism } \\
\hline 0.00 & 29.68 & 64.4 & 0.52 & 0.78 & 12.1 & 27.81 & 0 & 15.24 & 0.35 & 0.09 & -0.93 & -0.93 & -0.62 & 0.41 \\
\hline 0.25 & 29.78 & 64.56 & 0.51 & 0.78 & 2.28 & 6.51 & 11.92 & 14.26 & 0.35 & 0.09 & -0.73 & -0.74 & -0.25 & 0.54 \\
\hline 0.50 & 29.92 & 64.76 & 0.51 & 0.78 & 0.48 & 2.60 & 13.87 & 14.33 & 0.35 & 0.09 & -0.46 & -0.49 & -0.19 & 0.57 \\
\hline 0.75 & 30.01 & 65.01 & 0.51 & 0.78 & 0 & 1.31 & 14.31 & 14.37 & 0.35 & 0.09 & -0.27 & -0.23 & -0.18 & 0.57 \\
\hline \multicolumn{15}{|c|}{ Type II Paternalism } \\
\hline 0.25 & 30.16 & 64.58 & 0.51 & 0.78 & 0 & 2.90 & 13.96 & 14.40 & 0.35 & 0.09 & $>-0.20$ & -0.54 & -0.18 & 0.57 \\
\hline 0.50 & 30.00 & 65.32 & 0.51 & 0.78 & 0 & 0.75 & 14.31 & 14.39 & 0.35 & 0.09 & $>-0.30$ & 0.02 & -0.18 & 0.58 \\
\hline 0.75 & 29.93 & 65.71 & 0.51 & 0.78 & 0 & 0.12 & 14.38 & 14.38 & 0.36 & 0.09 & $>-0.32$ & 0.57 & -0.17 & 0.58 \\
\hline
\end{tabular}

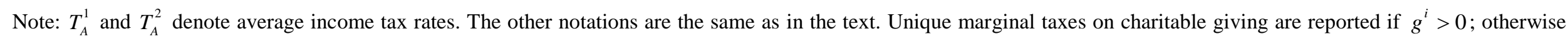
inequality conditions are reported. For example, $>-0.30$ means that the marginal tax rate should be higher than -0.3 (i.e., that the subsidy should be lower than 0.3 ). 
Correspondingly, there is a substantial reduction in the socially optimal level of charitable giving for both ability types. Indeed, for a sufficiently large $\mu$, we obtain a corner solution of zero giving for the low-ability type in both the welfarist and the Type I paternalist case. We can also note that the average tax rates, and in particular the average tax rate facing the lowability type, increase when $\mu$ increases. This largely reflects the need for additional tax revenue to finance the increased governmental contribution to the public good, i.e., contributions by the government replace the charitable contributions. The level and distribution of the private consumption (or income net of tax) do not change much in response to variation in $\mu$.

For sufficiently small transaction costs, we arrive at a corner solution with zero governmental provision of the public good under welfarism and Type I paternalism. The intuition is that if there are no transaction costs of such giving, and since the givers at the same time derive utility from giving, it may be optimal for the government not to contribute at all and instead delegate the public good provision completely to private charity. It should also be noted that we have not reported any results for Type II paternalism when $\mu=0$. The reason is similar to the reason why we did not report any result for large enough values of $\sigma$ in the Type II paternalist case. ${ }^{27}$

\section{Conclusions}

We have developed and analyzed a model where individuals give to charity through voluntary contributions to a public good, and where the government can contribute to this public good by raising tax revenue. In doing so, we assumed that income and charitable giving are observable at the individual level, while individual productivity (as reflected in the before-tax wage rate) is private information. Whereas this information structure rules out type-specific lump-sum taxes, it allows for general, nonlinear taxation of income and charitable giving. The basic research problem was to analyze to what extent the government should supply the public good and to what extent it should support (or tax) charitable giving. Furthermore, we took a broad perspective by examining the potential, simultaneous roles that the warm glow of giving and status concerns - defined in terms of relative consumption and relative charitable giving - may play for people's behavior and public policy. We also distinguished

\footnotetext{
${ }^{27} \mathrm{~A}$ very low value of $\mu$, implying large charitable giving by the high-ability type, together with the optimum result of zero charitable giving by the low-ability type imply that the utility term for charitable giving will not be defined for the low-ability type.
} 
between the policies decided on by a conventional welfarist government and those decided on by paternalist governments. Two versions of paternalism were addressed: one where the government does not respect people's relative consumption and relative charitable giving concerns (referred to as Type I paternalism) and the other where the government respects neither these relative concerns nor the consumer preference for warm glow (referred to as Type II paternalism). The models we used are based on the two-type model of optimal taxation pioneered by Stern (1982) and Stiglitz (1982), appropriately extended to cover the policy problems at hand.

We would like to emphasize four general results based on the theoretical analysis. First, the policy rules for marginal income taxation and public good provision take the same form as in the absence of any charitable giving. This is so because we have access to a direct and flexible tax instrument to target charitable giving (which is publically observable).

Second, the policy rules for marginal taxation or subsidization of charitable giving depend on the transaction cost associated with such giving and on the degrees of consumption and charitable giving positionality (since the decision to give to charity depends on the tradeoff between giving and private consumption). For low-ability individuals, the marginal tax treatment of charitable giving also depends on the difference in the marginal willingness to pay for charitable giving between the low-ability type and a potential mimicker. These results follow under both welfarism and Type I paternalism. However, whereas the corrective motive for taxing charitable giving under welfarism depends on the average degrees of charitable giving positionality and consumption positionality (which reflect the two positional externalities), the corrective component under paternalism depends on the type-specific degrees of charitable giving positionality and consumption positionality (which reflect the behavioral failure caused by the relative concerns).

Third, a corner solution where the government does not directly contribute to the public good (which arises if the voluntary contributions lead to overprovision compared with the secondbest optimal policy rule) motivates higher marginal taxation (or lower marginal subsidization) of charitable giving, ceteris paribus. This insight also applies under both welfarism and Type I paternalism. Taken together, therefore, the second and third general results imply that the policy rules for marginal taxation/subsidization of charitable giving are similar, despite that the two governments have very different motives for using corrective taxes/subsidies. 
Furthermore, these similarities extend to the policy rules for marginal income taxation and public good provision.

Fourth, the marginal tax treatment of charitable giving is much less generous under Type II paternalism than under the other two regimes. While it may be socially desirable that both ability types contribute to charity under welfarism and Type I paternalism, the low-ability type should never contribute to charity under Type II paternalism. However, despite the fact that such a government respects neither the relative concerns nor the consumer preference for warm glow, it may still be socially desirable that the high-ability type contributes to charity, since contributions by this type will relax the self-selection constraint.

Extensive numerical simulations confirm all these results. The simulations also show that the similarities between governments in terms of policy rules carry over to similarities in terms of levels of marginal taxation and overall redistribution policy. Given the assumptions on which the numerical model is based (in terms of functional forms and parameter values), we typically find that charitable giving should be subsidized at the margin. More specifically, the levels of public good provision and the overall redistribution policies are similar under all three regimes, and the marginal subsidies directed at charitable giving are very similar under welfarism and Type I paternalism. Under Type II paternalism, the government will always tax charitable giving by the low-ability type at a high enough rate to ensure that people in this group do not contribute voluntarily. The marginal subsidies directed at contributions by the high-ability type (when such contributions are socially desirable) are much lower under Type II paternalism than under the other regimes and may even turn into a marginal tax. Therefore, direct governmental provision of the public good plays a much more important role under the more extensive form of paternalism.

Overall, while we conclude - based on our theoretical as well as our numerical results - that there is often a case for subsidizing charitable giving, this is not always the expected outcome. In particular, the case for such subsidies is severely limited either by a government that does not value the utility arising from the warm-glow of giving or by high transaction costs associated with charitable giving. 


\section{Appendix}

\section{Proof of Proposition 1}

Consider first the marginal income tax rate implemented for the low-ability type. By combining equations (15) and (17), and then using $M R S_{z, c}^{1}=u_{z}^{1} / u_{c}^{1}$, we obtain

$$
\gamma n^{1}\left(w^{1}-M R S_{z, c}^{1}\right)=\lambda \hat{u}_{c}^{2}\left[M R S_{z, c}^{1}-\phi M \hat{R} S_{z, c}^{2}\right]-M R S_{z, c}^{1} \frac{n^{1}}{N} L_{\bar{c}}
$$

where $M \hat{R} S_{z, c}^{2}=\hat{u}_{z}^{2} / \hat{u}_{c}^{2}$. Equation (10) implies (for $\left.\mathrm{i}=1,2\right)$

$$
v_{\Delta c}^{i}=\alpha^{i}\left(v_{c}^{i}+v_{\Delta c}^{i}\right)=\alpha^{i} u_{c}^{i}=-u_{\bar{c}}^{i}
$$

and similarly for the mimicker. Substituting equation (A2) into equation (22) gives

$$
L_{\bar{c}}=-u_{c}^{1} \alpha^{1}-(\mu+\lambda) u_{c}^{2} \alpha^{2}+\lambda \hat{u}_{c}^{2} \hat{\alpha}^{2} .
$$

Next, using equations (15) and (16) to derive

$$
\begin{aligned}
& u_{c}^{1}=\lambda \hat{u}_{c}^{2}+\gamma n^{1}-\frac{n^{1}}{N} L_{\bar{c}} \\
& (\delta+\lambda) u_{c}^{2}=\gamma n^{2}-\frac{n^{2}}{N} L_{\bar{c}}
\end{aligned}
$$

and then substituting into equation (A3), we obtain

$$
\begin{aligned}
L_{\bar{c}} & =-\alpha^{1}\left(\lambda \hat{u}_{c}^{2}+\gamma n^{1}-\frac{n^{1}}{N} L_{\bar{c}}\right)-\alpha^{2}\left(\gamma n^{2}-\frac{n^{2}}{N} L_{\bar{c}}\right)+\lambda \hat{u}_{c}^{2} \hat{\alpha}^{2}, \\
& =L_{\bar{c}} \bar{\alpha}-\gamma N \bar{\alpha}+\lambda \hat{u}_{c}^{2}\left(\hat{\alpha}^{2}-\alpha^{1}\right)=\gamma N \frac{-\bar{\alpha}+\alpha^{d}}{1-\bar{\alpha}},
\end{aligned}
$$

where $\alpha^{d}=\frac{\lambda \hat{u}_{c}^{2}\left(\hat{\alpha}^{2}-\alpha^{1}\right)}{\gamma N}$

By substituting equation (A4) into equation (A1) and using $w^{1} T_{w l}^{1}=w^{1}-M R S_{z, c}^{1}$, we have

$$
\begin{aligned}
T_{w l}^{1} & =\frac{\lambda \hat{u}_{c}^{2}}{\gamma n^{1} w^{1}}\left[M R S_{z, c}^{1}-\phi M \hat{R} S_{z, c}^{2}\right]+\frac{M R S_{z, c}^{1}}{w^{1}} \frac{\bar{\alpha}-\alpha^{d}}{1-\bar{\alpha}}, \\
& =\tau^{1}+\frac{M R S_{z, c}^{1}}{w^{1}}\left(\frac{\bar{\alpha}}{1-\bar{\alpha}}-\frac{\alpha^{d}}{1-\bar{\alpha}}\right)
\end{aligned}
$$

where $\tau^{1}=\frac{\lambda \hat{u}_{c}^{2}}{\gamma n^{1} w^{1}}\left(M R S_{z, c}^{1}-\phi M \hat{R} S_{z, c}^{1}\right)$. 
Finally, using $M R S_{z, c}^{1} / w^{1}=1-T_{w l}^{1}$ from the private first-order condition, substituting into equation (A5), solving for $T_{w l}^{1}$, and rearranging gives equation (24) for the low-ability type. The marginal income tax rate implemented for the high-ability type can be derived in the same general way by combining equations (8), (16), and (18).

Turning to public good provision, rewrite equations (15) and (16) as follows:

$$
\begin{aligned}
& u_{c}^{1}=\lambda \hat{u}_{c}^{2}+\gamma n^{1}-\frac{n^{1}}{N} L_{\bar{c}}, \\
& (\delta+\lambda) u_{c}^{2}=\gamma n^{2}-\frac{n^{2}}{N} L_{\bar{c}} .
\end{aligned}
$$

Substitute into equation (21) to derive

$$
M R S_{G, c}^{1}\left(\lambda \hat{u}_{c}^{2}+\gamma n^{1}-\frac{n^{1}}{N} L_{\bar{c}}\right)+M R S_{G, x}^{2}\left(\gamma n^{2}-\frac{n^{2}}{N} L_{\bar{c}}\right)-\lambda M \hat{R} S_{G, c}^{2} \hat{u}_{c}^{2}-\gamma=0 .
$$

Collecting terms and rearranging gives

$$
\sum_{i} n^{i} M R S_{G, c}^{i}-\sum_{i} n^{i} M R S_{G, c}^{i} \frac{1}{\gamma N} L_{\bar{c}}+\frac{\lambda \hat{u}_{c}^{2}}{\gamma}\left[M R S_{G, c}^{1}-M \hat{R} S_{G, c}^{2}\right]=1
$$

Substituting equation (A4) into equation (A7) gives equation (25).

\section{Proof of Proposition 2}

Let us start by deriving an expression for the partial welfare effect of an increase in the level of reference giving, $\bar{g}$. Note that by using $u_{\bar{g}}^{i}=-\beta^{i} u_{g}^{i}$, we can rewrite equation (23) as

$$
L_{\bar{g}}=u_{\bar{g}}^{1}+(\delta+\lambda) u_{\bar{g}}^{2}-\lambda \hat{u}_{\bar{g}}^{2}=-\beta^{1} u_{g}^{1}-(\delta+\lambda) \beta^{2} u_{g}^{2}+\lambda \hat{\beta}^{2} \hat{u}_{g}^{2} .
$$

Then, using $u_{G}^{1}+(\delta+\lambda) u_{G}^{2}-\lambda \hat{u}_{G}^{2}=\gamma$ from equation (21), we can rewrite equations (19) and (20) to read

$$
\begin{aligned}
u_{g}^{1} & =\lambda \hat{u}_{g}^{2}-u_{G}^{1}(1-\mu) n^{1}-(\delta+\lambda) u_{G}^{2}(1-\mu) n^{1}+\lambda \hat{u}_{G}^{2}(1-\mu) n^{1}+\gamma n^{1}-\frac{n^{1}}{N} L_{\bar{g}} \\
& =\lambda \hat{u}_{g}^{2}-(1-\mu) n^{1}\left(u_{G}^{1}+(\delta+\lambda) u_{G}^{2}-\lambda \hat{u}_{G}^{2}\right)+\gamma n^{1}-\frac{n^{1}}{N} L_{\bar{g}} \\
& =\lambda \hat{u}_{g}^{2}-(1-\mu) \gamma n^{1}+\gamma n^{1}-\frac{n^{1}}{N} L_{\bar{g}} \\
& =\lambda \hat{u}_{g}^{2}+\eta \gamma n^{1}-\frac{n^{1}}{N} L_{\bar{g}}
\end{aligned}
$$




$$
\begin{aligned}
(\delta+\lambda) u_{g}^{2} & =-u_{G}^{1}(1-\mu) n^{2}-(\delta+\lambda) u_{G}^{2}(1-\mu) n^{2}+\lambda \hat{u}_{G}^{2}(1-\mu) n^{2}+\gamma n^{2}-\frac{n^{2}}{N} L_{\bar{g}} . \\
& =\mu \gamma n^{2}-\frac{n^{2}}{N} L_{\bar{g}}
\end{aligned} .
$$

Substituting equations (A9) and (A10) into equation (A8) leads to

$$
L_{\bar{g}}=-\beta^{1}\left(\lambda \hat{u}_{g}^{2}+\mu \gamma n^{1}-\frac{n^{1}}{N} L_{\bar{g}}\right)-\beta^{2}\left(\mu \gamma n^{2}-\frac{n^{2}}{N} L_{\bar{g}}\right)+\lambda \hat{\beta}^{2} \hat{u}_{g}^{2} .
$$

Collecting terms gives

$$
L_{\bar{g}}=-N \mu \gamma \frac{\bar{\beta}}{1-\bar{\beta}}-\frac{\lambda \hat{u}_{g}^{2}}{1-\bar{\beta}}\left(\beta^{1}-\hat{\beta}^{2}\right)=\gamma N \frac{-\mu \bar{\beta}+\beta^{d}}{1-\bar{\beta}},
$$

where $\beta^{d} \equiv\left(\hat{\beta}^{2}-\beta^{1}\right) \lambda \hat{u}_{g}^{2} /(\gamma N)$.

Consider first the marginal tax treatment of the charitable giving by the low-ability type. By combining equations (15) and (19), we obtain

$$
\frac{u_{g}^{1}}{u_{c}^{1}}\left(\lambda \hat{u}_{c}^{2}+\gamma n^{1}-\frac{n^{1}}{N} L_{\bar{c}}\right)-\lambda \hat{u}_{g}^{2}-\gamma n^{1} \mu+\frac{n^{1}}{N} L_{\bar{g}}=0 .
$$

Using the private first-order condition $u_{g}^{1} / u_{c}^{1}=1+T_{g}^{1}$ and the definition of the private marginal rates of substitution between charitable giving and private consumption, we can rewrite equation (A12) to read

$$
\left(1+T_{g}^{1}\right) \gamma n^{1}=\lambda \hat{u}_{c}^{2}\left(M \hat{R} S_{g, c}^{2}-M R S_{g, c}^{1}\right)+\gamma n^{1} \mu-\frac{n^{1}}{N}\left(L_{\bar{g}}-M R S_{g, c}^{1} L_{\bar{c}}\right) .
$$

Substituting equations (A4) and (A11) into equation (A13) gives

$$
1+T_{g}^{1}=\frac{\lambda \hat{u}_{c}^{2}}{\gamma n^{1}}\left(M \hat{R} S_{g, c}^{2}-M R S_{g, c}^{1}\right)+\mu+\frac{\mu \bar{\beta}-\beta^{d}}{1-\bar{\beta}}-M R S_{g, c}^{1} \frac{\bar{\alpha}-\alpha^{d}}{1-\bar{\alpha}} .
$$

Using $\operatorname{MRS}_{g, c}^{1}=1+T_{g}^{1}$ in the final term on the right-hand side of equation (A14), collecting terms, and rearranging give equation (30). The marginal tax on charitable giving by the highability type can be derived in the same general way by combining equations (9), (16), and (20).

\section{Proof of Proposition 4}

Consider first the marginal income tax implemented for the low-ability type. Combining equations (17) and (48) gives 


$$
\frac{v_{z}^{1}}{v_{c}^{1}}\left(\lambda\left(\hat{v}_{c}^{2}+\hat{v}_{\Delta c}^{2}\right)+\gamma n^{1}-\frac{n^{1}}{N} L_{c}=\lambda \phi \hat{u}_{z}^{2}+\gamma n^{1} w^{1} .\right.
$$

Using the SMRS functions defined in the text, we can rewrite equation (A15) to read

$$
\gamma n^{1}\left(w^{1}-S M R S_{z, c}^{1}\right)=\lambda \hat{v}_{c}^{2}\left[S M R S_{z, c}^{1}-\phi S M \hat{R} S_{z, c}^{2}\right]+S M R S_{z, c}^{1}\left[\lambda \hat{v}_{\Delta c}^{2}-\frac{n^{1}}{N} L_{c}\right] .
$$

Substituting $L_{\bar{c}}=\lambda\left(-u_{\Delta}^{2}+\hat{u}_{\Delta}^{2}\right)$ and the private first-order condition for work hours, which can be written as $w^{1}-S M R S_{z, c}^{1}=w^{1} T_{w l}^{1}-S M R S_{z, c}^{1} \alpha^{1}$, into equation (A16), we obtain equation (54). Equation (55) can be derived in the same general way by combining equations (8), (18), and (49).

To derive the policy rule for the public good, note that equations (48) and (49) can be written as

$$
\begin{aligned}
& v_{c}^{1}=\lambda\left(\hat{v}_{c}^{2}+\hat{v}_{\Delta c}^{2}\right)+\gamma n^{1}-\frac{n^{1}}{N} L_{\bar{c}}, \\
& \delta v_{c}^{2}=-\lambda\left(\hat{v}_{c}^{2}+\hat{v}_{\Delta c}^{2}\right)+\gamma n^{2}-\frac{n^{2}}{N} L_{\bar{c}} .
\end{aligned}
$$

Substituting into equation (21), while using $S M R S_{G, c}^{i}=v_{G}^{i} / v_{c}^{i}=u_{G}^{i} / v_{c}^{i}$, gives

$$
\begin{aligned}
& \operatorname{SMRS}_{G, c}^{1}\left(\lambda\left(\hat{v}_{c}^{2}+\hat{v}_{\Delta c}^{2}\right)+\gamma n^{1}-\frac{n^{1}}{N} L_{\bar{c}}\right)+\operatorname{SMRS}_{G, c}^{2}\left(-\lambda\left(\hat{v}_{c}^{2}+\hat{v}_{\Delta c}^{2}\right)+\gamma n^{2}-\frac{n^{2}}{N} L_{\bar{c}}\right) . \\
& \quad+\lambda v_{G}^{2}-\lambda \hat{v}_{G}^{2}-\gamma=0
\end{aligned}
$$

Equation (A17) can be rearranged to read

$$
\begin{gathered}
\gamma \sum_{i} n^{i} S M R S_{G, c}^{i}+\lambda \hat{v}_{c}^{2}\left(S M R S_{G, c}^{1}-S M \hat{R} S_{G, c}^{2}\right)+S M R S_{G, c}^{1}\left(\lambda \hat{v}_{\Delta c}^{2}-\frac{n^{1}}{N} L_{\bar{c}}\right) \\
+\operatorname{SMRS}_{G, c}^{2}\left(-\lambda v_{\Delta c}^{2}-\frac{n^{2}}{N} L_{\bar{c}}\right)-\gamma=0
\end{gathered}
$$

Using equation (52) in equation (A18) and rearranging give equation (56).

\section{Proof of Proposition 5}

Consider first the marginal tax treatment of charitable giving by the low-ability type. If we combine equations (48) and (50), we can write the social first-order condition for charitable giving as

$$
\operatorname{SMRS}_{g, c}^{1}\left(\lambda\left(\hat{v}_{c}^{2}+\hat{v}_{\Delta c}^{2}\right)+\gamma n^{1}-\frac{n^{1}}{N} L_{\bar{c}}=0\right)-\lambda\left(\hat{v}_{g}^{2}+\hat{v}_{\Delta g}^{2}\right)-\gamma n^{1} \mu+\frac{n^{1}}{N} L_{\bar{g}}=0,
$$


where we have used $\operatorname{SMR} S_{g, c}^{1}=v_{g}^{1} / v_{c}^{1}$. Note that the private first-order condition for charitable giving (expressed in terms of the function $\left.v^{1}(\cdot)\right)$ can be written as

$$
S M R S_{g, c}^{1}=-\frac{v_{\Delta g}^{1}}{v_{c}^{1}}+\left(1+\frac{v_{\Delta c}^{1}}{v_{c}^{1}}\right)\left(1+T_{g}^{1}\right) .
$$

In addition, note that

$$
\begin{aligned}
& 1+\frac{v_{\Delta c}^{1}}{v_{c}^{1}}=\frac{1}{1-\alpha^{1}} \\
& \frac{v_{\Delta g}^{1}}{v_{c}^{1}}=\frac{\beta^{1}}{1-\beta^{1}} S M R S_{g, c}^{1} .
\end{aligned}
$$

Substituting into equation (A19) and rearranging give

$$
\begin{aligned}
\left(-\frac{\beta^{1}}{1-\beta^{1}} S M R S_{g, c}^{1}+\frac{1}{1-\alpha^{1}}\left(1+T_{g}^{1}\right)\right) \gamma n^{1} & =\lambda \hat{v}_{c}^{2}\left(S M \hat{R} S_{g, c}^{2}-S M R S_{g, c}^{1}\right) \\
& -S M R S_{g, c}^{1} \lambda \hat{v}_{\Delta c}^{2}+\lambda \hat{v}_{\Delta g}^{2} \\
& +\gamma n^{1} \mu-\frac{n^{1}}{N}\left(L_{\bar{g}}-S M R S_{g, c}^{1} L_{\bar{c}}\right)
\end{aligned} .
$$

Finally, using equations (52) and (53) in equation (A20), and the private first order condition to substitute for the SMRS function in the final row, as well as using the relationship

$$
\frac{1-\alpha^{1}}{1-\beta^{1}} S M R S_{g, c}^{1}=M R S_{g, c}^{1},
$$

we obtain equation (57). Equation (58) can be derived in the same general way by combining equations (9), (49), and (51).

\section{First-Order Condition for $g^{1}$ under Type II paternalism}

By using equation (21), the derivative of the Lagrangean with respect to $g^{1}$ can be written as

$$
L_{g^{1}}=-\lambda\left(\hat{v}_{g}^{2}+\hat{v}_{\Delta g}^{2}\right)-\gamma \mu n^{1}-\frac{n^{1}}{N} \lambda\left(v_{\Delta g}^{2}-\hat{v}_{\Delta g}^{2}\right)<0
$$

for $g^{1} \geq 0$.

\section{Proof of Proposition 7}

To derive the policy rule for the marginal tax on charitable giving by the high-ability type, we combine equations (9), (49), and (64) and then proceed along the same lines as in the proof of Proposition 5 to derive 


$$
-\frac{\beta^{2}}{1-\beta^{2}} S M R S_{g, c}^{2}+\frac{1}{1-\alpha^{2}}\left(1+T_{g}^{2}\right)=S M R S_{g, c}^{2} \lambda\left(\frac{\left(v_{c}^{2}+v_{\Delta c}^{2}\right)+\frac{n^{2}}{N} L_{\bar{c}}}{\gamma n^{2}}\right)+\delta \frac{v_{g}^{2}}{\gamma n^{2}} .
$$

Use the private first-order condition

$$
S M R S_{g, c}^{2}=-\frac{\beta^{2}}{1-\beta^{2}} S M R S_{g, c}^{2}+\frac{1}{1-\alpha^{2}}\left(1+T_{g}^{2}\right)
$$

to substitute in the first term on the right-hand side of equation (A22), and equation (52) to substitute for $L_{\bar{c}}$. Finally, using equation (64) to solve for $v_{g}^{2} / \gamma n^{2}$ and substituting into equation (A22) gives equation (65).

\section{References}

Abel, A.B., (2005) Optimal Taxation When Consumers Have Endogenous Benchmark Levels of Consumption. Review of Economic Studies 72, 1-19.

Akerlof, G.A., (1997) Social Distance and Social Decisions. Econometrica 65, 1005-1028.

Alpízar, F., F. Carlsson, and O. Johansson-Stenman (2005) How Much Do We Care about Absolute versus Relative Income and Consumption? Journal of Economic Behavior and Organization 56, 405-21.

Alpizar, F., F. Carlsson, and O. Johansson-Stenman, (2008) Anonymity, Reciprocity and Conformity: Evidence from Voluntary Contributions to a National Park in Costa Rica. Journal of Public Economics 92, 1047-1060.

Andreoni, J., (1998) Toward a Theory of Charitable Fund-Raising. Journal of Political Economy 106, 1186-1213.

Andreoni, J., (1989) Giving with Impure Altruism: Applications to Charity and Ricardian Equivalence. Journal of Political Economy 97, 1447-1458.

Andreoni, J., (1990) Impure Altruism and Donations to Public Goods: A Theory of WarmGlow Giving. Economic Journal 100, 464-77.

Andreoni, J. and R. Petrie, (2004). Public Goods Experiments without Confidentiality: a Glimpse into Fund-raising. Journal of Public Economics 88, 1605-1623.

Andreoni, J., J. M. Rao and H. Trachtman (2017) Avoiding the Ask: A Field Experiment on Altruism, Empathy, and Charitable Giving. Journal of Political Economy 125, 625-53.

Aronsson, T., O. Johansson-Stenman, (2008) When the Joneses' Consumption Hurts: Optimal Public Good Provision and Nonlinear Income Taxation. Journal of Public Economics 92, 986-997. 
Aronsson, T., O, Johansson-Stenman, (2010) Positional Concerns in an OLG Model: Optimal Labor and Capital Income Taxation. International Economic Review 51, 1071-1095.

Aronsson, T., O, Johansson-Stenman, (2014) When Samuelson met Veblen Abroad: National and Global Public Good Provision When Social Comparisons Matter. Economica 81, 224-243.

Aronsson, T., O. Johansson-Stenman (2018) Paternalism Against Veblen: Optimal Taxation and Non-Respected Preferences for Social Comparisons. American Economic Journal: Economic Policy 10, 39-76.

Aronsson, T., O. Johansson-Stenman, and R. Wendner (2018) Redistribution through Charity and Optimal Taxation when People are Concerned with Social Status. Unpublished Manuscript.

Atkinson, A.B., (1976) The Income Tax Treatment of Charitable Contributions. In: Grieson, R. (Ed.), Public and Urban Economics: Essays in the Honor of William S. Vickrey. D.C. Heath, New York.

Auten, G., H. Sieg, C.T. Clotfelter, (2002) Charitable Giving, Income and Taxes: An Analysis of Panel Data. American Economic Review 92, 371-382.

Becker, G. S. (1993) Nobel Lecture: The Economic Way of Looking at Behavior. Journal of Political Economy 101, 385-409.

Besley, T., S. Coate, (1992) Understanding welfare stigma: Taxpayer resentment and statistical discrimination, Journal of Public Economics 48, 165-184.

Blackorby, C., W. Bossert, D. Donaldson, (2005) Population Issues in Social Choice Theory, Welfare Economics and Ethics. New York: Cambridge University Press.

Blanchflower, D.G., A.J. Oswald, (2004) Well-Being Over Time in Britain and the USA. Journal of Public Economics 88, 1359-1386.

Bergstrom, T., L. Blume, and H. Varian (1985) On the Private Provision of Public Goods. Journal of Public Economics 29, 25-49.

Blomquist S., L. Micheletto, (2006) Optimal Redistributive Taxation when Government's and Agents' Preferences Differ. Journal of Public Economics 90, 1215-33.

Blumkin, T., E. Sadka, (2007) A case for taxing charitable donations. Journal of Public Economics 91 (7-8), 1555-1564.

Boskin, M.J., E. Sheshinski, (1978) Individual Welfare Depends Upon Relative Income. Quarterly Journal of Economics 92, 589-601.

Bowles, S., Y. Park, (2005) Emulation, Inequality, and Work Hours: Was Thorsten Veblen Right? Economic Journal 115, F397-F412. 
Bursztyn, L., B. Ferman, S. Fiorin, M. Kanz and G. Rao (2017), Status Goods: Experimental Evidence from Platinum Credit Cards, NBER working paper 23414.

Carlsson, F., O. Johansson-Stenman, P. Martinsson, (2007) Do You Enjoy Having More Than Others? Survey Evidence of Positional Goods. Economica 74, 586-598.

Cartwright, E., A. Patel, (2013) How Category Reporting can Improve Fundraising. Journal of Economic Behavior and Organization 87, 73-90.

Clark, A.E., A.J. Oswald, (1994) Unhappiness and Unemployment, Economic Journal 104, $648-659$.

Clark, A., C. Senik, (2010) Who Compares to Whom? The Anatomy of Income Comparisons in Europe. Economic Journal 120, 573-594.

Clotfelter, C.T. (Ed.), (1992) Who Benefits from the Nonprofit Sector. The University of Chicago Press, Chicago.

Clotfelter, C.T., (2014) Charitable Giving and Tax Policy in the U.S. In: Fack, G., C. Landais (Eds.), Charitable Giving and Tax Policy: A Historical and Comparative Perspective. Oxford, Oxford University Press.

DellaVigna, S., J. List, U. Malmendier, (2012) Testing for Altruism and Social Pressure in Charitable Giving. Quarterly Journal of Economics 127, 1-56.

Diamond, P., (1980) Income Taxation with Fixed Hours of Work. Journal of Public Economics 13(1): 101-110.

Diamond, P., (2006) Optimal Tax Treatment of Private Contributions for Public Goods with and Without Warm-Glow Preferences. Journal of Public Economics 90, 897-919.

Dodds, S. (2012) Redistributive Taxation and Heterogeneous Relative Consumption Concerns. Canadian Journal of Economics 45, 220-46.

Dupor, B., W.F. Liu, (2003) Jealousy and Overconsumption. American Economic Review 93, 423-428.

Easterlin, R.A., (2001) Income and Happiness: Towards a Unified Theory. Economic Journal 111, 465-484.

Eckerstorfer, P., R. Wendner (2013) Asymmetric and Non-Atmospheric Consumption Externalities, and Efficient Consumption Taxation, Journal of Public Economics 106, 42-56.

Fack, G. and C. Laindais, eds., (2012) Charitable Giving and Tax Policy: A Historical and Comparative Perspective. Conference Volume, CEPR/CEPREMAP Conference on Altruism and Charitable Giving held in May 2012, Paris School of Economics. 
Feldstein, M., (1980) A Contribution to the Theory of Tax Expenditures: The Case of Charitable Giving. In: Aaron, H. J., and M. J. Boskin (Eds.), The Economics of Taxation, Essays in Honor of Joseph Peckman, 99-122. Brookings Institution, Washington, D.C.

Ferrer-i-Carbonell, A., (2005) Income and Well-being: An Empirical Analysis of the Comparison Income Effect. Journal Public Economics 89, 997-1019.

Galí, J., (1994) Keeping Up with the Joneses: Consumption Externalities, Portfolio Choice and Asset Prices. Journal of Money, Credit, and Banking 26, 1-8.

Glazer, A., K. Konrad, (1996) A Signaling Explanation for Charity. American Economic Review 86, 1019-1028.

Goodin, R. E. (1986) Laundering Preferences. In Foundations of Social Choice Theory, edited by J. Elster and A. Hylland. Cambridge: Cambridge University Press.

Harbaugh, W., (1998a) What do Donations Buy? A Model of Philanthropy Based on Prestige and Warm Glow. Journal of Public Economics 67, 269-284.

Harbaugh, W., (1998b) The Prestige Motive for Making Charitable Transfers. American Economic Review 88, 277-282.

Harsanyi, J. (1982) Morality and the Theory of Rational Behavior. In Utilitarianism and Beyond, edited by Sen, A. and Williams, B. Cambridge: Cambridge University Press.

Johansson-Stenman, O., F. Carlsson, D. Daruvala, (2002) Measuring Future Grandparents' Preferences for Equality and Relative Standing. Economic Journal 112, 362-383.

Kanbur, R., M. Tuomala. (2013) Relativity, Inequality and Optimal Nonlinear Income Taxation. International Economic Review 54, 1199-1217.

Kaplow, L., (1995) A note on subsidizing gifts. Journal of Public Economics 58, 469-477.

Kaplow, L., (1998) Tax policy and gifts. American Economic Review: Papers and Proceedings 88, 283-288.

Karlan D., M.A. McConnell, (2014) Hey Look at Me: The Effect of Giving Circles on Giving. Journal of Economic Behavior \& Organization 106 (C), 402-412.

Kleven, H., W. Kopczuk, (2011) Transfer program complexity and the takeup of social benefits. American Economic Journal: Economic Policy 3, 54-90.

Layard, R., (1980) Human Satisfaction and Public Policy. Economic Journal 90, 737-750.

Ljungqvist, L., Uhlig, H., (2000) Tax Policy and Aggregate Demand Management Under Catching Up with the Joneses. American Economic Review 90, 356-366.

Micheletto, L. (2011) Optimal Nonlinear Redistributive Taxation and Public Good Provision in an Economy with Veblen Effects. Journal of Public Economic Theory 13, 71-96. 
Moffit, R., (1983) An economic model of welfare stigma, American Economic Review 75, $1023-1035$.

Oswald, A., (1983) Altruism, Jealousy and the Theory of Optimal Non-Linear Taxation. Journal of Public Economics 20, 77-87.

Reinstein, D., G. Riener, (2012) Decomposing Desert and Tangibility Effects in a Charitable Giving Experiment. Experimental Economics 15, 229-240.

Roberts, R.D., (1987) Financing Public Goods. Journal of Political Economy 95, 420-437.

Sen, A.K., (1983) Development: Which Way Now? The Economic Journal 93, 745-762.

Sen, A.K., (1999) Development as Freedom (ed. A. Knopf), New York: Oxford University Press.

Saez, E., (2004) The Optimal Treatment of Tax Expenditures. Journal of Public Economics $88,2657-2684$.

Sen, A. K. (1979) Personal Utilities and Public Judgments: or What's Wrong with Welfare Economics. Economic Journal 89, 537-558.

Solnick, S., D. Hemenway, (2005) Are Positional Concerns Stronger in Some Domains than in Others? American Economic Review, Papers and Proceedings 45, 147-151.

Stiglitz, J.E., (1982) Self-Selection and Pareto Efficient Taxation. Journal of Public Economics 17, 213-240.

Thaler, R. H. (2017) Behavioral Economics, Journal of Political Economy125, 99-105.

Warr, P., (1982). Pareto optimal redistribution and private charity. Journal of Public Economics 19, 131-138.

Wendner, R., L.H. Goulder, (2008) Status Effects, Public Goods Provision, and the Excess Burden. Journal of Public Economics 92, 1968-1985. 